OPEN ACCESS

Edited by:

Marialessandra Contino, University of Bari Aldo Moro, Italy

Reviewed by:

Eva Martínez-Pinilla, Universidad de Oviedo Mieres, Spain Diego Guidolin,

University of Padova, Italy

${ }^{*}$ Correspondence: Estefanía Moreno estefaniamoreno@ub.edu Enric Canela ecanela@ub.edu

Specialty section: This article was submitted to Experimental Pharmacology and Drug Discovery,

a section of the journal

Frontiers in Pharmacology

Received: 28 December 2018

Accepted: 19 March 2019

Published: 05 April 2019

Citation:

Moreno E, Cavic M, Krivokuca A, Casadó V and Canela E (2019) The Endocannabinoid System as a Target

in Cancer Diseases: Are We There Yet? Front. Pharmacol. 10:339. doi: 10.3389/fphar.2019.00339

\section{The Endocannabinoid System as a Target in Cancer Diseases: Are We There Yet?}

\author{
Estefanía Moreno ${ }^{1,2 *},{\text { Milena } \text { Cavic }^{3} \text {, Ana Krivokuca }}^{3}$, Vicent Casadó ${ }^{1,2}$ and \\ Enric Canela ${ }^{1,2 *}$
}

${ }^{1}$ Department of Biochemistry and Molecular Biomedicine, Faculty of Biology, Institute of Biomedicine (IBUB), University of Barcelona, Barcelona, Spain, ${ }^{2}$ Centro de Investigación Biomédica en Red sobre Enfermedades Neurodegenerativas (CIBERNED), Madrid, Spain, ${ }^{3}$ Department of Experimental Oncology, Institute for Oncology and Radiology of Serbia, Belgrade, Serbia

The endocannabinoid system (ECS) has been placed in the anti-cancer spotlight in the last decade. The immense data load published on its dual role in both tumorigenesis and inhibition of tumor growth and metastatic spread has transformed the cannabinoid receptors $\mathrm{CB} 1$ (CB1R) and $\mathrm{CB} 2$ (CB2R), and other members of the endocannabinoidlike system, into attractive new targets for the treatment of various cancer subtypes. Although the clinical use of cannabinoids has been extensively documented in the palliative setting, clinical trials on their application as anti-cancer drugs are still ongoing. As drug repurposing is significantly faster and more economical than de novo introduction of a new drug into the clinic, there is hope that the existing pharmacokinetic and safety data on the ECS ligands will contribute to their successful translation into oncological healthcare. CB1R and CB2R are members of a large family of membrane proteins called G protein-coupled receptors (GPCR). GPCRs can form homodimers, heterodimers and higher order oligomers with other GPCRs or non-GPCRs. Currently, several CB1R and CB2R-containing heteromers have been reported and, in cancer cells, CB2R form heteromers with the G protein-coupled chemokine receptor CXCR4, the G protein-coupled receptor 55 (GPR55) and the tyrosine kinase receptor (TKR) human V-Erb-B2 Avian Erythroblastic Leukemia Viral Oncogene Homolog 2 (HER2). These protein complexes possess unique pharmacological and signaling properties, and their modulation might affect the antitumoral activity of the ECS. This review will explore the potential of the endocannabinoid network in the anti-cancer setting as well as the clinical and ethical pitfalls behind it, and will develop on the value of cannabinoid receptor heteromers as potential new targets for anti-cancer therapies and as prognostic biomarkers.

Keywords: endocannabinoids, G protein-coupled receptor, cannabinoid CB1 receptor, cannabinoid CB2 receptor, ethical issues, marijuana legalization, receptor heteromer 


\section{INTRODUCTION}

The term endocannabinoid system (ECS) refers to a complex network of cannabinoid receptors, endocannabinoid ligands, the enzymatic machinery that drives their biosynthesis, degradation, transport and all cells and neurological pathways that involve endocannabinoid signaling (Figure 1). It is implicated in the control of the most vital processes thus creating homeostasis within the organism, which explains its ambiguous role in tumorigenesis and suppression of tumors.

The ECS components were gradually described in the late 1980s and early 1990s during the search for the pharmacological targets of $\Delta$ 9-tetrahydrocannabinol (THC) isolated from the plant Cannabis sativa (marijuana) (Devane et al., 1988; Matsuda et al., 1990). The discovery was a classical success story that went much beyond the intended purpose of providing mechanistic proof for the psychotropic effects of cannabinoids. As cannabinoid consumption was alarmingly rising especially in more developed countries, a lot of funding was invested in projects trying to decipher the exact mode of its action in order to strengthen the publics "no" vote for marijuana legalization (Thomas, 2001). However, the fact that marijuana was also invaluable in easing the symptoms of many other conditions (nausea, pain, motor dysfunctions, cardiovascular, gastrointestinal and reproductive problems etc.) could not be ignored for long. Considering the range of its benefits, it was obvious that all these effects must be explained through the action of various active components of $C$. sativa not on a single target in the brain but rather on a more complex entity.

The ECS has been placed in the anti-cancer spotlight in the last decade. The immense data load published on its dual role in both tumorigenesis and inhibition of tumor growth and metastatic spread has made it into attractive new target for the treatment of various cancer subtypes. Although the search

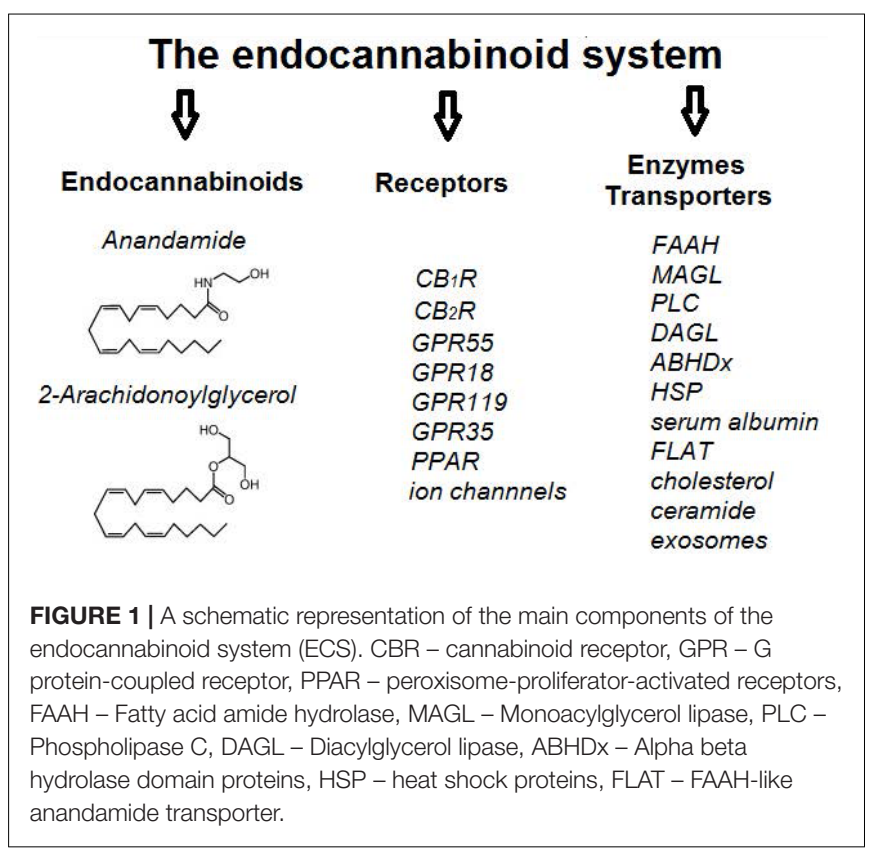

for cancer biomarkers usually favors single targets that enable the exploitation of a biochemical or genetic weakness, marking the vast ECS as a pharmacologically targetable entity brings as many advantages as complications. This review will explore the potential of the ECS in the anti-cancer setting as well as the clinical and ethical pitfalls behind it, and will develop on the value of cannabinoid receptor heteromers as potential new targets for anti-cancer therapies and as prognostic biomarkers.

\section{THE DISCOVERY OF THE CANNABINOID RECEPTORS}

The first components of the ECS that were discovered were THC target sites in the brain. These receptors were named cannabinoid receptors (CBR), but it was still unknown that they represent one of the most abundant neurotransmitter receptors in the whole organism. The first discovered and cloned receptor was named CB1R (Matsuda et al., 1990) and it was concluded that THC exerts a presynaptic inhibition of normal endogenous signaling of this receptor leading to the known psychotropic effects in the central nervous system (CNS) (Roth, 1978). The second identified ECS receptor was found in non-CNS sites, mostly on cells of the immune system, and was named CB2R (Munro et al., 1993). This discovery was a promising start for the search of the other factors involved in the non-psychotropic effects of cannabinoids, as it was found that ligands of CB2R are responsible for their observed immunomodulatory effects (Acharya et al., 2017). Both receptors are expressed in the periphery as well, regulating vital processes in the gastrointestinum, lungs, skin, kidneys, reproductive system, liver, lymph nodes, bones, etc.

The human central cannabinoid receptor gene 1 (CNR1) is located on chromosome 6 (6q15, HGNC ID: 2159) (HUGO), and it encodes three isoforms of a $60 \mathrm{kDa}$ CB1R protein (UniProtKB P21554) (UniProtKB). It is expressed in CNS areas that control motor behavior, memory and learning, emotions, sensory and endocrine functions, as well as in peripheral nerves and in other extra-neural locations (Atwood and Mackie, 2010). CB1R are mostly located presynaptically and mainly coupled to inhibitory $\mathrm{Gi} / \mathrm{o}$ proteins, which among other effects inhibit adenylate cyclase and lead to a decrease of intracellular cAMP levels. The activation of CB1R at glutaminergic and GABAergic neuron membranes by endocannabinoids inhibits the release of excitatory and inhibitory neurotransmitters (glutamate, GABA, acetylcholine, dopamine, D-aspartate, noradrenaline, etc.). Thus, CB1R and its ligands contribute to the plasticity of neurotransmission, and are attractive pharmacological targets.

The human central cannabinoid receptor gene 2 (CNR2) is located on chromosome 1 (1p36.11, HGNC ID: 2160) (HUGOb) and it encodes multiple isoforms of a $40 \mathrm{kDa}$ CB2R protein (UniProtKB - P34972) (UniProtKBb). CB2R are also mostly located presynaptically and mainly coupled to inhibitory Gi/o proteins, so 2-AG and other CB2R ligands have various roles in the regulation of immune responses and peripheral neurotransmission. The CB2R was firstly detected in the immune system (Pertwee et al., 2010), but over time its expression was also detected in other cell types. The presence of CB2R in microglial 
cells during neuroinflammation has been well documented, but it has also been detected in astrocytes and some subpopulations of neurons (Munro et al., 1993; Fernandez-Ruiz et al., 2007; Atwood and Mackie, 2010). As agonists that bind to CB2R usually lack the psychotropic effects seen upon CB1R agonistbased treatments, the selective targeting of CB2R in the CNS and the periphery might be a perspective approach for the treatment of various neurological disorders.

\section{CB1R and CB2R Are GPCRs}

Cannabinoid receptors belong to an extensive family of class $\mathrm{A}$ rhodopsin-like G-protein coupled receptors (GPCR), important for transducing signals from the extracellular space to a variety of intracellular signaling molecules (Matsuda et al., 1990; Munro et al., 1993; Pertwee et al., 2010). It is not by chance that the ECS receptors are GPCRs, as the chemical variety of ligands that bind and activate them is extraordinary. GPCRs form the most extensive human membrane protein family, with about 826 members in the human proteome (Cvicek et al., 2016; Shimada et al., 2018). According to their sequence homology, phylogenetic analyses and after the Human Genome Project was completed, Fredriksson et al. (2003) classified GPCRs into five families: rhodopsin (class A, 701 members), secretin (class B, 15 members), glutamate (class C, 15 members), adhesion (24 members) and frizzled/taste (class F, 24 members). Currently, IUPHAR identifies six main classes: the A-F classes, containing human receptors, and classes D and E, including GPCRs of other species with no human orthologs (Sharman and Mpamhanga, 2011). GPCRs are main players in cell communication and transduce sensory signals of external origin, such as odorants and taste molecules, light and endogenous stimuli such as hormones, neuropeptides, neurotransmitters, purine ligands, chemokines, calcium ions, etc. Recently, conformational modifications that mediate GPCR activation have been described, as well as the structural conformation of the receptors necessary to interact with the three classes of proteins that preferentially bind to activated GPCRs: heterotrimeric G proteins, GPCR kinases and $\beta$-arrestins (Vilardaga et al., 2010; González et al., 2014; Wells, 2014; Gurevich and Gurevich, 2017; Wang et al., 2017).

$\mathrm{G}$ protein-coupled receptors, also known as heptahelical or seven-transmembrane (TM) receptors, are cell surface proteins with a common topology comprised by an extracellular (EC) $\mathrm{N}$-terminus and a cytoplasmic C-terminus with an amphiphilic $\alpha$-helix (H8) alongside the cell membrane. They have 7 TM $\alpha$-helices connected by 3 intracellular (ICL) and 3 extracellular loops (ECL) and a disulphide bridge between ECL2 and TM3 (González et al., 2014; Baltoumas et al., 2016). The 7TM bundle can be divided into $\mathrm{EC}$ and IC regions. The $\mathrm{N}$-terminus varies in length from relatively short and unstructured (such as many class A members) to long and with many globular domains and conserved secondary structure (such as class $\mathrm{C}$ members). The IC module includes the ICLs, a short helix 8 and an IC C-terminus (Katritch et al., 2012; Di Pizio et al., 2016); it is more conserved among GPCRs, in contrast to the EC region, and is responsible for interaction with intracellular proteins implicated in feedback modulation and signal transduction of receptor function (Moreira, 2014; Di Pizio et al., 2016).

The orthosteric binding site of a receptor is the canonical site where the natural ligand binds. Its location can vary markedly between different subclasses of GPCRs and can be found in different positions within the TM bundle or in an extracellular pocket. Ligand binding to this orthorteric site produces conformational changes in the receptor's cytosolic region facilitating binding and the activation of downstream signaling effectors such as $\beta$-arrestins and G proteins (Staus et al., 2016). The orthosteric binding pocket can bind both native or synthetic ligands termed orthosteric ligands. Other ligands targeting GPCRs are currently classified as allosteric, bitopic/dualsteric or bivalent ligands (Feng et al., 2015).

However, elucidation of the GPCRs crystal structures, along with molecular modeling and functional studies, provides insight into the binding mode of natural or synthetic ligands and open new opportunities for the design of next-generation GPCR drugs. In the last years, the number of receptors that have been crystallized has greatly increased and more than 250 structures of 50 different GPCRs have been solved in complex with agonists, antagonists, antibodies, peptides or G proteins (Venkatakrishnan et al., 2013; Shonberg et al., 2015; Shimada et al., 2018). From the elucidated crystal structures of class A GPCRs, it is deduced that ligand binding occurs in a main pocket found between the EC segments of TMs 3, 5, 6, and 7 or in a minor cavity found between the EC segments of TMs 1, 2, 3, and 7 (Gonzalez et al., 2014). Although GPCRs present these common cavities, different ligands can penetrate to various depths within the TM bundle, so that this structural core binds ligands in the EC module and transfers the information to the IC module. It is the most conserved structural component of GPCRs, showing characteristic hydrophobic patterns and functional motifs (Katritch et al., 2012; Di Pizio et al., 2016). Structural studies with class A receptors, have revealed the existence of a conformational change upon receptor activation which include a breaking of "the ionic lock formed between TM6 and the D(E)RY motif in TM3, and movements of the TM5 and TM6 cytoplasmic segments and the ICL3," with some minor rearrangements in the TM3 helix (Baltoumas et al., 2016).

In the case of cannabinoid receptors, unbiased molecular dynamics has demonstrated that a ligand can penetrate the binding pocket of a class A GPCR via the lipid bilayer. Effectively, Hurst et al. (2010), using microsecond time scale all-atom molecular dynamics (MD) simulations, showed that the endogenous cannabinoid $s n$-2-arachidonoylglycerol (2-AG) accesses to the $\mathrm{CB} 2 \mathrm{R}$ passing throughout the lipid bilayer. Their results suggest that $2-\mathrm{AG}$ penetrates the $\mathrm{CB} 2 \mathrm{R}$ binding pocket by passing between TM6 and TM7 (Hurst et al., 2010). In 2016, Shao et al. (2016) crystallized the human CB1R thermostabilized by the inverse agonist taranabant, and solved its atomic structure at $2.6-\AA$ resolution. They confirmed a gap between TM1 and TM7 in the EC leaflet that could contribute to a membraneembedded access channel for lipophilic agonists of CBRs. In order to facilitate the entry of ligands, a subsequent dilatation of the conserved residues (Ile119 ${ }^{1.35}$, Phe381 7.37 , and Met384 $4^{7.40}$ ) would be required. At the same time, Hua et al. (2016) crystallized 
CB1R bound to AM6538, an antagonist with a nitrate group substituted on the chlorophenyl moiety of rimonabant. The two structures are in good agreement, but the taranabantbound and AM6538-bound CB1R structures represent an inactive conformation with respect to G-protein binding. Later, Hua et al. (2017) reported two crystal structures of human CB1R in complex with agonists: a hexahydrocannabinol (AM841) and a tetrahydrocannabinol (AM11542), with a resolution of 2.95 and $2.80 \AA$, respectively. These CB1R-agonist complexes showed relevant conformational changes compared with the CB1Rantagonist structures, that is, a 53\% reduction in the volume of the ligand-binding pocket and an increment in the surface of the G-protein binding region (Hua et al., 2017).

\section{GPCRs Form Oligomeric Protein Complexes}

Since the early 80 s the concept on intramembrane receptorreceptor interactions was introduced and the first experimental evidence was reported for their existence in crude membrane preparations from different CNS areas (Agnati et al., 1980; Fuxe et al., 1981; Fuxe and Agnati, 1985). Since then, many evidence show that GPCRs do not act exclusively as monomeric proteins (Agnati et al., 2005; Fuxe et al., 2007). Kniazeff et al. (2011) reviewed that dimer formation is a prerequisite for canonical receptor function in class C GPCRs, and Xue et al. (2015) demonstrated that the mGluR2 dimer interface switches from TM4-TM5 in the inactive state to TM6-TM6 interactions in the active conformation, revealing a key step in class C GPCR activation. In the large subfamily A of GPCRs, although several receptors are able to operate as monomers (Chabre and le Maire, 2005; Ernst et al., 2007; Hanson et al., 2007; Whorton et al., 2007, 2008; Kuszak et al., 2009; Arcemisbéhère et al., 2010; Bayburt et al., 2011), experimental data have shown that most receptors could be expressed as a mixture of monomers and homodimers/oligomers (Teichmann et al., 2014; Vischer et al., 2015; Franco et al., 2016; Nemoto et al., 2016), and that oligomerization is necessary for the maturation of the receptor, its inclusion in the membrane and its function (Angers et al., 2000, 2002; Fotiadis et al., 2003; Herrick-Davis et al., 2006; Lopez-Gimenez et al., 2007; Han et al., 2009; Wade et al., 2011; $\mathrm{Ng}$ et al., 2013; Hurevich et al., 2014; Liste et al., 2015; Gahbauer and Böckmann, 2016; Lao et al., 2017; Jin et al., 2018). Fung et al. (2009) reported receptor oligomers, mostly with tetrameric structure, of $\beta 2$-adrenergic receptors after reconstitution into phospholipid vesicles. Albizu et al. (2010) demonstrated the in vivo existence of native oxytocin receptor dimers and Herrick-Davis et al. (2012, 2013, 2015) provided strong experimental evidence that adrenergic, muscarinic, dopamine, and serotonin $5-\mathrm{HT}_{2} \mathrm{C}$ receptors form homodimers endogenously expressed in their cellular environment. Using dual color photoactivation localization microscopy with photoactivatable dyes, Jonas et al. (2015) reported that the luteinizing hormone receptor (LHR) is organized in a mixture of monomers, dimers and lower order oligomers at the plasma membrane with distinct spatial geometries. Likewise, M1 muscarinic receptor, D2 dopamine receptor, $\beta_{1}$-adrenergic receptor and chemokine receptor (CXCR4) can exist in a dynamic equilibrium between monomers/dimers/oligomers, that can be regulated by selective agonists, antagonists or bivalent ligands (Calebiro et al., 2013; Pediani et al., 2016; Tabor et al., 2016). Cai et al. (2017) demonstrated monomer-todimer interconversion of the class A apelin receptor (APJ) on the cell membrane, with APJ dimers possessing new functional characteristics after agonist activation, such as distinct G-protein binding profile and cell responses. Recently, Parmar et al. (2017), using BRET, bimolecular fluorescence complementation (BiFC) and fluorescence correlation spectroscopy (FCS) indicated that the $\beta_{2}$-adenergic receptors are predominantly homodimers, and Jastrzebska et al. (2017) demonstrated that the human red cone opsin forms a stable dimer in the live cell membrane with the existence of three essential amino acids, I230, A233 and M236 that are required for dimerization.

Furthermore, a multitude of other class A GPCRs have been also found to form homomers, specially in the last decade, such as cannabinoid $\mathrm{CB}_{1}$, adenosine $\mathrm{A}_{1}, \mathrm{~A}_{2 \mathrm{~A}}$ and $A_{3}$, adrenergic $\alpha_{1 B}$, dopamine $D_{1}$ and $D_{3}$, serotonin $5 \mathrm{HT}_{1 \mathrm{~A}}, 5 \mathrm{HT}_{2} \mathrm{~A}$, and $5 \mathrm{HT}_{7}, \delta, \kappa$ and $\mu$ opioid, angiotensin $\mathrm{AT}_{1}$, muscarinic $\mathrm{M}_{2}$ and $\mathrm{M}_{3}$, melatonin $\mathrm{MT}_{2}$, and niacin receptors (Cvejic and Devi, 1997; Jordan and Devi, 1999; He et al., 2002; Ayoub et al., 2004; Goin and Nathanson, 2006; Łukasiewicz et al., 2007; Mandrika et al., 2010; Teitler et al., 2010; Gracia et al., 2011, 2013; May et al., 2011; Pou et al., 2012; Szalai et al., 2012; Herrick-Davis et al., 2013; Guitart et al., 2014; Bonaventura et al., 2015; Bagher et al., 2017).

$G$ protein-coupled receptors are not only present as monomers and homomers but also form heteromers with other GPCRs (Smith and Milligan, 2010; Ferré et al., 2014; Gomes et al., 2016a; Farran, 2017; Gaitonde and González-Maeso, 2017; Guidolin et al., 2018). GPCR heteromers with two or more receptor protomers are macromolecular complexes with biochemical properties clearly different from those of its individual components (Ferré et al., 2009, 2014; Gomes et al., 2016a). Three consensus criteria have been published by the International Union of Basic and Clinical Pharmacology to classify a true GPCR heteromers (Kenakin et al., 2010). The first criterion indicates that the heteromer components must co-localize to the same subcellular compartment and physically interact in native tissues (Albizu et al., 2010; Hounsou et al., 2015; Gomes et al., 2016a). The second consensus criteria requires that the heteromers must exhibit specific properties, that differ from those associated with the individual protomers, such as trafficking, ligand binding and signaling (biochemical fingerprint) (Jordan and Devi, 1999; Hillion et al., 2002; Terrillon et al., 2004; Sohy et al., 2007; Gomes et al., 2011, 2016a; González et al., 2012; Kern et al., 2012; Bellot et al., 2015; Jonas et al., 2018). Finally, criterion 3 postulates that heteromer disruption brings about a loss of interaction and, therefore, to a loss of the typical biochemical fingerprint of the heteromer (Baba et al., 2013; Fujita et al., 2015; Gomes et al., 2016a). Respect to the second criterion, according to Cortés et al. (2016), there are three major allosteric modulations in GPCR heteromers that imply alterations of the affinity and/or efficacy of a ligand by a protomer 
within the heteromer due to binding of an allosteric modulator in any site of the heteromer, or to binding of an orthosteric ligand in the other protomer or to the simple presence of the other protomer within the heteromer (Kenakin and Miller, 2010; Wootten et al., 2013; Ferré et al., 2014; Ferré, 2015; Casadó-Anguera et al., 2016).

Although many GPCR heteromers have been identified using heterologous cell lines, only very few fit all three criteria. This is mainly due to the difficulties to study these structures in native tissues because of the lack of sensitive and selective enough tools, able to detect in vivo evidence of these endogenous heteromers and to demonstrate that they are close enough to interact (Gomes et al., 2016b). Therefore, the accomplishment of at least two out of three criteria is required for the acceptance of a GPCR heteromer (Jonas and Hanyaloglu, 2017). The main strategies to target GPCR heteromers are the generation of selective compounds, which exhibit higher efficacy in tissues from wild type animals or in cells expressing both receptors than in knock-out animals tissues or in cell only expressing the individual receptors (Akgün et al., 2013; Gomes et al., 2013a; Molero et al., 2015; Nimczick and Decker, 2015; Peterson et al., 2017). Likewise, the use of membrane-permeable peptides that target the dimerization interface or heteromer-selective antibodies that can recognize an epitope in the heteromer but not in the individual protomers, have been most useful to detect GPCRs heteromers in vivo (Gupta et al., 2010; He et al., 2011; Viñals et al., 2015; Gomes et al., 2016a; Moreno et al., 2017; Jacobs et al., 2018). Finally, it is important to note the existence of single-molecule techniques, which are ideal for understanding the conformational complexity and dynamic signaling of GPCRs (Tian et al., 2017). Their application in living cells can provide the tools to directly visualize individual receptors in homomers and heteromers and how GPCRs can move about and interact in the presence of diverse ligands (Jonas et al., 2016; Scarselli et al., 2016; Calebiro and Sungkaworn, 2018).

A basic heterotetrameric structure formed by two homomers of a $\mathrm{G}_{s}$-coupled and a $\mathrm{G}_{i}$-coupled receptor has been reported for the dopamine D1-D3 receptor heteromer (Guitart et al., 2014), the adenosine A1-A2A receptor heteromer (Navarro et al., 2016), the adenosine A2A-dopamine D2 receptor heteromer (Bonaventura et al., 2015; Casadó-Anguera et al., 2016; Borroto-Escuela et al., 2018; Navarro et al., 2018), and the adenosine A1-dopamine D1 receptor heteromer (Rivera-Oliver et al., 2018).

\section{Cannabinoid Receptors Heteromers}

Cannabinoid receptors have been described for a long time as constituents of particular GPCR receptor heteromers. CB1Rs have been demonstrated in the past to interact with other GPCRs, such as adenosine $\mathrm{A}_{2 \mathrm{~A}}$ receptors (Carriba et al., 2007; Moreno et al., 2018), dopamine $\mathrm{D}_{2}$ receptors (producing a change in the coupling from Gi to Gs) (Glass and Felder, 1997; Kearn et al., 2005; Marcellino et al., 2008), $\mathrm{D}_{2}$ and adenosine $\mathrm{A} 2 \mathrm{~A}$ receptors at the same time (generating a negative modulation of the function of $\mathrm{D}_{2}$ receptor by $\mathrm{A} 2 \mathrm{~A}$ and CB1 agonists) (Carriba et al., 2008; Navarro et al., 2010;
Bonaventura et al., 2014), opioid $\mu$ and $\delta$ receptors (producing a negative cross-talk between receptors) (Rios et al., 2006), orexin $\mathrm{OX}_{1}$ receptors (producing a positive cross-talk and crossantagonism by orexin) (Hilairet et al., 2003; Ellis et al., 2006), angiotensin $\mathrm{AT}_{1}$ receptors (with an increase of $\mathrm{AT}_{1}$ receptor signaling) (Rozenfeld et al., 2011), CB2R (negative cross-talk and bidirectional cross-antagonism in neuronal cells in culture and in vivo is produced by the coactivation of both receptors) (Callén et al., 2012), adrenergic $\beta_{2}$ receptor (adrenergic agonists inducing CB1R internalization) (Hudson et al., 2010), and $5 \mathrm{HT}_{2 \mathrm{~A}}$ serotonin receptor (Viñals et al., 2015). Also, CB1R can form heteromers with the cannabinoid-related orphan receptor GPR55 in HEK-293 cells (Kargl et al., 2012; Martínez-Pinilla et al., 2014). Contrary to CB1R, not much is known about the existence and functional importance of heteromers concerning CB2R, however, there is evidence of its interaction with GPR55 in transfected cells (Balenga et al., 2014) and with CXCR4 (Coke et al., 2016; Scarlett et al., 2018).

\section{THE DISCOVERY OF ENDOCANNABINOIDS}

The first discovered and most abundant endocannabinoids were anandamide (N-arachidonoyl ethanolamide, AEA) (Devane et al., 1992) and 2-arachydonoyl glycerol (2-AG) (Mechoulam et al., 1995), derivatives of $\omega-6$ arachidonic acid (ARA), an essential polyunsaturated fatty acid (PUFA). Beside AEA and 2-AG, other unsaturated lipid-based molecules have been classified as endocannabinoids due to their function and comparably high levels ( $\mathrm{N}$-arachidonoyl dopamine, N-oleoyldopamine, homo linoleoyl ethanolamide (HEA), docosa tetraenyl ethanolamide, virodhamine, noladin ether, palmitoyl ethanolamide, oleoylethanolamide, oleamide, eicosapentaenoylethanolamide, sphingosine, hemopressin, etc.) (Pertwee, 2015; Nikan et al., 2016). The significance of these small molecules is highlighted by the fact that their signaling pathways exist even in very primitive organisms where they regulate a range of vital processes (De Petrocellis et al., 1999). They are produced and are active inside the body upon demand, and they exert a regulatory role of adaptive cellular responses to various endogenous and environmental stimuli that endanger internal homeostasis.

Endocannabinoid signaling is not a classical example of neurotransmission, as their effects are mostly restricted to local sites of their biosynthesis and release. Their biosynthesis precedes the stimuli, and they are stored in synaptic vesicles until needed. Once they have exerted their effect on the receptors of postsynaptic neurons, they are transported back to the presynaptic neuron terminating the short-lived response to a stimulus (Lu and Mackie, 2016). As exogenous cannabinoids are usually supplied in excess they can take over the endocannabinoid signaling for longer time periods, leading to a range of physiological effects. Beside $\mathrm{CB} 1 \mathrm{R}$ and $\mathrm{CB} 2 \mathrm{R}$, other receptors have been found to be the targets of endocannabinoids and exocannabinoids in the CNS and in tumor tissues, including the transient receptor potential channels, ligand and voltage-gated 
ion channels and other orphan $\mathrm{G}$ protein-coupled receptors as GPR55, GPR18 and GPR119 (Soderstrom et al., 2017). Receptorindependent regulatory effects of endocannabinoids have also been documented, contributing to the plasticity of the ECS (Lu and Mackie, 2016).

\section{Non-ARA Based Endocannabinoids}

Beside the most common endocannabinoid derivatives of ARA, other classes of lipid-based molecules important for the ECS have been detected in high enough levels to be classified as endocannabinoids (McDougle et al., 2017). $\omega$-3 PUFAs, such as docosahexaenoic acid (DHA) and eicosapentaenoic acid (EPA), convert to a range of biologically active molecules important for proper functioning of essential biochemical processes in the body. These epoxyeicosatetraenoic acid-ethanolamides (EEQEA) and epoxydocosapentaenoic acid-ethanolamides (EDPEA) are formed through the action of cytochrome P450 epoxygenase, and have been found to preferentially stimulate CB2Rs and induce anti-inflammatory and antiangiogenic effects (McDougle et al., 2017). The complexity of the ECS can also be seen in the constant interplay of $\omega-3$ and $\omega-6$ PUFA based endocannabinoids, as well as in the sharing of the biosynthetic/degradative and regulatory levels by various classes of endocannabinoids, which influences the final outcome of a specific stimuli (Dyall, 2017).

\section{Binding of Endo- and Exocannabinoids to Cannabinoid Receptors}

Exogenous cannabinoids (plant-derived and synthetic) bind to CBRs as their binding pocket is flexible and can interact with ligands that are not the exact size and shape match to their designated endocannabinoids (Sim-Selley, 2003). As a consequence, all the processes regulated by endocannabinoids are susceptible to the interference of exogenous cannabinoids (allosteric, bitopic/dualsteric or bivalent ligands), and their effects have been extensively documented in various settings (pregnancy/infertility, motor functions, CNS development, etc). THC binds to CB1R instead of anandamide on neurons, but also to CB2R on immune cells which changes the endogenous response to infection and also reduces inflammation. 2-AG also has a mimetic plant cannabinoid called cannabidiol (CBD) which exerts its mostly health promoting effects by competing with 2-AG for its binding places on CB2R and other receptors (Iffland and Grotenhermen, 2017). These effects are even more pronounced in conditions where ECS signaling is impaired (Clinical Endocannabinoid Deficiency) due to external factors as stress, diet, medicaments or internal ones involving a dysbalance between the biosynthesis, breakdown and transport of endocannabinoids (Russo, 2016). Thus, the observed clinical benefits of exogenous cannabinoids have a strong biochemical rational.

However, the effects of exocannabinoids cannot be considered as a simple receptor-takeover as they do not act as mere substitutes for endocannabinoids. Depending on their concentration, abundance of receptors and the levels and activity of endogenous ligands and enzymes, agonism, antagonism and inverse agonism of cannabinoid and non-cannabinoid receptors can occur (Pertwee, 2015; Lu and Mackie, 2016). In vitro evidence shows that around 13 endogenous compounds have been detected so far that can bind to these receptors orthosterically or allosterically (Pertwee, 2015), while AEA and 2-AG are the main orthosteric ligands.

Apart from orthosteric ligands, several allosteric modulators for CBRs have been discovered. While cannabinoids interact with the orthosteric receptor site, these novel CBR ligands bind the receptor at sites topographically distinct from the orthosteric binding site, modifying the receptor conformation and leading its novel properties and modes of action (Conn et al., 2009; Fay and Farrens, 2013; Shore et al., 2014; Stornaiuolo et al., 2015; Foster and Conn, 2017). The allosteric cannabinoid ligands modulate the CBR activity by altering the affinity and/or the efficacy of an orthosteric ligand in either a positive (positive allosteric modulator, PAM) or negative (negative allosteric modulator, NAM) manner. In the last decade, many allosteric modulators for CB1R have been reported (Nguyen et al., 2017; Scott and Kendall, 2017; Dopart et al., 2018). Examples of CB1R NAM are ORG27569, ORG27759, and ORG29647 (Price et al., 2005; Ahn et al., 2013), PSNCBAM-1 (Horswill et al., 2007), pepcans (Bauer et al., 2012), pregnenolone (Vallée et al., 2014) and CBD (Laprairie et al., 2015). CB1R PAM are RTI-371 (Navarro et al., 2009), lipoxin A4 (Pamplona et al., 2012), GAT211 and its enantiomer GAT229 (Laprairie et al., 2017b), and ZCZ011 (Ignatowska-Jankowska et al., 2015). Recently, some modulators of $\mathrm{CB} 2 \mathrm{R}$ have also been described; MartínezPinilla et al. (2017) reported that CBD could also act as a NAM of CB2R because it is able to negatively modulate the binding and functional effect of CB2R agonists; Petrucci et al. (2017) reported that pepcan-12 is a potent CB2R PAM and, very recently, Pandey et al. (2019) described DHGA and TBC as CB2R NAMs, decreasing the binding of the orthosteric agonist CP55,940. The therapeutic usefulness of these cannabinoid allosteric modulators is emerging, and they offer an exciting potential for mechanistic analyses and for the development of therapeutics (Scott and Kendall, 2017).

\section{THE DISCOVERY OF THE ENDOCANNABINOID ENZYMATIC AND TRANSPORT SYSTEMS}

The last ECS component that was described in more detail was the enzymatic machinery behind the biosynthesis, degradation and transport of endocannabinoids. Endocannabinoids are lipid neuromodulators produced on-demand making the ECS a fast acting and adaptive entity. Anandamide and 2arachydonoyl glycerol have very similar chemical structures (Figure 1) but the pathways involved in their biosynthesis and degradation are completely different, highlighting their distinct physiological roles. They are both derivatives of arachidonic acid, an essential PUFA, but while anandamide 
is synthesized mostly from $\mathrm{N}$-arachidonoyl phosphatidyl ethanol by various pathways, 2-AG is produced mainly from phosphatidyl inositol bis-phosphate in a calciumdependent manner involving phospholipase C (PLC) and diacylglycerol lipase (DAGL) (Lu and Mackie, 2016). Also, fatty acid amide hydrolase (FAAH) primarily hydrolyzes AEA in the endoplasmic reticulum, and monoacylglycerol lipase (MAGL) is the primary hydrolytic degrader of 2-AG, with FAAH and some serine hydrolases (ABHD6 and ABHD12) as proposed secondary degraders (Savinainen et al., 2012). Levels of endogenous cannabinoids depend also on the activity of their uptake and effective transport in the cell, as they are hydrophobic and cannot diffuse through the cytosol and cell membrane easily. Many carriers and molecules have been implicated in this process depending on the cell type, as heat shock proteins, serum albumin and other fatty-acid binding proteins as FAAH-like anandamide transporter (FLAT), cholesterol, ceramides (Nicolussi and Gertsch, 2015; Di Scala et al., 2018). Once AEA reaches the target receptors on cells, and exerts its effects, it is recycled back to the cytoplasm and is subjected to enzymatic hydrolysis. Some exogenous cannabinoids, as CBD for example, can interfere with AEA FAAH-mediated breakdown, raising the levels of available AEA, thus indirectly inducing various non-psychoactive effects (Bisogno et al., 2001).

\section{ECS COMPONENTS IN ANTI-CANCER THERAPY}

The mechanisms involved in the regulation of ECS as well as the processes that it regulates include practically every pathway important in cancer biology. So it is not a matter of chance that ECS components can exert antiproliferative, proapoptotic, antiangiogenic, anti-metastatic and anti-inflammatory effects depending on tumor type and specific setting. Cannabinoid receptors and endocannabinoids are generally up-regulated in tumors (Sanchez et al., 2001; Guzmán, 2003; Caffarel et al., 2006; Malfitano et al., 2011), and their expression levels can be linked to tumor aggressiveness (Nomura et al., 2010; Thors et al., 2010; Malfitano et al., 2011). These data imply that an over-activation of ECS might be a pro-tumorigenic factor (Malfitano et al., 2011), but considering the complexity of this system, the effects it induces depend on many factors. The various implications of the ECS in different cancer types have been reviewed in Table 1.

\section{Cannabinoid Receptors in Cancer}

There are in vivo reports showing that genetic ablation of $\mathrm{CB} 1 \mathrm{R}$ and $\mathrm{CB} 2 \mathrm{R}$ leads lower the skin-cancer inducing potential of UV light (Zheng et al., 2008), and that overexpression of $\mathrm{CB} 2 \mathrm{R}$ contributes to a higher risk of leukemia upon leukemia virus infection (Joosten et al., 2002). On the contrary, there are reports implying that pharmacological activation of CBRs leads to a reduction of tumor growth (Guzmán, 2003; Sarfaraz et al., 2008), suggesting that ECS signaling might induce tumor-suppressive effects. This opinion is reinforced by in vivo reports that the deletion of CB1R accelerates tumor growth (Wang et al., 2008), that the presence of higher endocannabinoid levels lead to a reduction of precancerous lesions (Izzo et al., 2008), and that lower expression of MAGL decreases tumor growth (Nomura et al., 2010; Velasco et al., 2015).

The expression of $\mathrm{CB} 1 \mathrm{R}$ and $\mathrm{CB} 2 \mathrm{R}$ in cancer cells and the cells originating from the same tissue often does not correlate well (Guzmán et al., 2006; Fernandez-Ruiz et al., 2007; Sarfaraz et al., 2008; Velasco et al., 2012). Different types of tumor cells can over-express CB1R and/or CB2R and are as such very attractive for various anti-cancer approaches (Pagano and Borrelli, 2017). On the other side, there are reports that the loss of expression of $\mathrm{CB} 1 \mathrm{R}$ and/or $\mathrm{CB} 2 \mathrm{R}$ can lead to acceleration of tumor growth (Wang et al., 2008). Thus, their significance as prognostic and/or predictive factors for targeted therapies must be explored in more detail for each cancer subtype, especially when biased agonism is taken into account (Laprairie et al., 2017a). Exploring the ECS non-receptor mechanisms is also a promising approach, as receptor expression does not have a straight forward correlation with tumorigenicity (Soderstrom et al., 2017). There are reports that the activation of CBRs leads to apoptosis of tumor cells and inhibition of their dissemination through the regulation of RAS/MAPK and PI3KAKT pathways (Pagano and Borrelli, 2017), TNF $\alpha$-induced ceramide synthesis (Cianchi et al., 2008), endoplasmic reticulum stress-related genes (Carracedo et al., 2006a), COX-2-dependent cell death (Patsos et al., 2010), inhibition

TABLE 1 | The implication of the endocannabinoid system in different cancer types.

\begin{tabular}{llll}
\hline ECS component & Type of effect & Cancer type & References \\
\hline CB1R & Gene/Protein overexpression & Glioma, astrocytoma & Galve-Roperh et al., 2000; Cudaback et al., 2010 \\
CB2R & Gene/Protein overexpression & $\begin{array}{l}\text { Glioma, melanoma, astrocytoma, } \\
\text { breast, hepatic, pancreatic cancer }\end{array}$ & $\begin{array}{l}\text { Sanchez et al., 2001; Lorente et al., 2011; Velasco } \\
\text { et al., 2012 }\end{array}$ \\
CB2R-CXCR4 & Heteromerization & Breast, prostate cancer & Coke et al., 2016; Scarlett et al., 2018 \\
CB2R-GPR55 & Heteromerization & Breast cancer & Moreno et al., 2014 \\
HER2-CB2R & Heteromerization & Breast cancer & Pérez-Gómez et al., 2015; Blasco-Benito et al., 2019 \\
Anandamide & Upregulation & Colon cancer & Patsos et al., 2010 \\
FAAH & Gene/Protein overexpression & Prostate cancer & Thors et al., 2010 \\
MAGL & Gene/Protein overexpression & Breast, ovarian, melanoma, colorectal & Granchi et al., 2017; Pagano et al., 2017
\end{tabular}


of neo-angiogenesis (Pisanti et al., 2007), and many other proposed mechanisms.

\section{Heteromers as Potential Targets}

Because GPCRs allosterically facilitate the transfer of information across the cytoplasmic membrane responding to extracellular signals, they acquire an essential role in the mediation of signal transduction. In turn, this renders GPCRs therapeutic targets in a wide number of diseases, either due to their capacity to regulate a set of signaling cascades implicated in a specific disease or due to their direct involvement in the pathophysiology of this disease (Lefkowitz, 2004; Cvicek et al., 2016). Over $90 \%$ of described GPCRs are expressed in the CNS and are crucial for the appropriate functioning of many neurological actions (Vassilatis et al., 2003). Thus, it is not surprising that, in clinical medicine, they are the most important class of membrane proteins. Currently, more than $30 \%$ of all US Food and Drug Administration (FDA) approved drugs target GPCRs (Shimada et al., 2018), and these drugs are utilized in a wide range of therapeutic areas, including cancer, inflammation and diseases of the CNS, cardiovascular, respiratory and gastrointestinal dysfunctions, diabetes, obesity, and pain (Feng et al., 2015). Hauser et al. (2017) pointed out that more than 300 agents were in clinical trials in that moment, of which around 60 targeted novel GPCRs for which no drug had yet been approved.

Nevertheless, despite "the proven success of GPCRs as drug targets, clinically useful ligands do not exist for the majority of GPCRs" (Ferré et al., 2014). This is probably because the true target of the GPCRs are not the individual (monomeric) receptors but heteromeric complexes with other GPCRs, other receptors or other membrane, cytosolic or extracellular proteins, in general. Thus, the monomeric strategy is no longer the most appropriate for developing clinically useful drugs and we hypothesize that the approach should be focused on heteromeric GPCRs. "A particular advantage of receptor heteromers as targets for drug development is that they can be involved in the pathophysiology of the disorder being targeted. Thus, the receptor heteromer would be more likely to be disease-specific than would the corresponding monomeric/homomeric receptors" (Cortés et al., 2016). Newer reports show that heteromer-selective drugs can exist in the form of small-molecules, bivalent or multifunctional ligands, or antibodies, displaying higher affinity and efficacy for a receptor that forms a certain heteromer than for this receptor in another heteromer or in the monomeric form (Orru et al., 2011; Gomes et al., 2013c,b, 2016a; Cortés et al., 2016; Pulido et al., 2018; Qian et al., 2018a,b).

In addition to heteromerization, drug discovery efforts for cannabinoid receptors also involve the use of allosteric cannabinoid ligands. One of the main problems of the use of orthosteric ligands is their lack of selectivity among the different members of a GPCR subfamily, because the orthosteric binding sites are highly conserved (Conn et al., 2009). However, the alosteric binding sites are less conserved and show greater selectivity across different receptor subtypes (Conn et al., 2009). The development of allosteric modulators of GPCRs in general, and of CBRs in particular, have emerged as new approaches for developing therapeutic drugs that may be useful for the treatment of CNS disorders, without the inherent side effects of orthosteric ligands (Foster and Conn, 2017; Nguyen et al., 2017; Scott and Kendall, 2017). The development of biased allosteric modulators of CB1R has also been showed as a promising way to selectively modulate a therapeutically desirable CB1R signaling pathway (Khajehali et al., 2015). Furthermore, there is the possibility that the dimerization of GPCRs, and CBRs, could lead to the appearance of an allosteric binding site, specific for the dimer and non-existent in the individual protomers. This new allosteric site has been reported for homocysteine in the A2AR-D2R heterodimer (Agnati et al., 2006; Cervetto et al., 2018).

\section{GXCR4-CB2R Heteromers in Cancer}

It has been reported that CB2R can form heteromers with the $\mathrm{G}$ protein-coupled chemokine receptor CXCR4 in human breast and prostate cancer cells (Coke et al., 2016; Scarlett et al., 2018). CXCR4 is implicated in various mechanism that enhance the cell's ability to proliferate and migrate, thus its activation has been linked to local and distant metastatic invasion. Upon the in vitro application of both CXCR4 and CB2R agonists however, a reduction of the cell's CXCR4-induced ERK1/2 dependent migration has been documented, most likely due to the presence of functional CXCR4-CB2R heteromers (Coke et al., 2016). This heteromerization might enable cannabinoids to indirectly reduce the invasive properties of cancer cells by inhibiting the effects of CXCR4 agonists. The presence of CXCR4 and CB2R agonists has also been associated with the inhibition of the Ga13/RhoA signaling pathway in prostate cancer cells. The levels of RhoA and Ga13 proteins decreased upon this dual stimulation, and led to an abolishment of the cytoskeletal changes necessary for directional cell migration (Scarlett et al., 2018). The invasive potential of the cells was further decreased by an observed reduction of integrin $\alpha 5$ expression in vitro, which is crucial for the cell's ability to adhere to the extracellular matrix. Over all, all these data identify a novel pharmacologic target for the modulation of tumor cell migration and invasion in the context of metastatic disease.

\section{GPR55-CB2R Heteromers in Cancer}

It has also been reported that CB2R and GPR55 are overexpressed in many of cancer types (Henstridge et al., 2011; Velasco et al., 2012), where they are crucial for the regulation of the cell fate (Henstridge et al., 2011; Andradas et al., 2011; Piñeiro et al., 2011; Velasco et al., 2012; Pérez-Gómez et al., 2013). As cannabinoids modulate the activity of GPR55, its anti-cancer effects have been analyzed as well.

CB2R/GPR55 transfected cells and breast cancer cells form GPR55-CB2R heteromers with unique pharmacological and signaling properties (Moreno et al., 2014). The expression of the GPR55-CB2R heteromers influences cannabinoid signaling in a way that their direct targeting using appropriate amounts of THC might lead to a reduction of tumor growth, both in vitro and in vivo. This is a promising new approach for the development of drugs that target these heteromers in future cancer-related studies. These results also help to explain the potential molecular mechanisms behind the documented but still poorly comprehended biphasic effects of cannabinoids, present 
in older reports concerning food intake, motor behavior, anxiety, and others (Sulcova et al., 1998; Sañudo-Peña et al., 2000; Moreira and Wotjak, 2010).

It might even be speculated that GPR55-CB2R heteromers could exist and be crucial at other cancer-related sites, such as bones or hematopoietic cells, where their overexpression has been detected (Whyte et al., 2009; Balenga et al., 2011).

\section{HER2-CB2R Heteromers in Cancer}

In breast cancer, the overexpression of the tyrosine kinase receptor (TKR) human V-Erb-B2 Avian Erythroblastic Leukemia Viral Oncogene Homolog 2 (HER2) is a particular hallmark of one type of this disease (Perou et al., 2000; Sorlie et al., 2001; Sotiriou et al., 2003; Curtis et al., 2012). The activation of TKRs engages crucial signaling pathways implicated in cellular proliferation, development, differentiation, angiogenesis, and other processes (Higgins and Baselga, 2011). Approximately 20-30\% of primary breast cancer cells exhibit HER2 gene amplification and protein overexpression which is a poor prognostic biomarker and leads to an inadequate response to chemotherapy (Moasser, 2007). At the same time, CB2R is overexpressed in breast cancer, and it is present in especially high levels in aggressive (high-grade) tumors (Caffarel et al., 2006; Qamri et al., 2009; Caffarel et al., 2010).

There are very few examples of physical interaction between RTKs and GPCRs, although several RTK-RTK heteromers and GPCR-GPCR heteromers have been previously described. Transactivation of RTKs by GPCRs and vice versa has been observed, and in most cases physical interactions suggested, but no solid evidence of the existence of heteromers has been demonstrated (Pyne and Pyne, 2011).

The best characterized RTK-GPCR heteromer is produced by HER2 and $\beta 2$-adrenergic receptors in the heart and it is essential for the cardiac homeostasis (Negro et al., 2006); by fibroblast growth factor receptor and adenosine A2A receptors (Flajolet et al., 2008) or serotonin 5-HT1A receptors (Borroto-Escuela et al., 2012), which take part in synaptic plasticity; and by EGFR and GPR54, which seem to induce breast cancer cell invasiveness (Zajac et al., 2011).

The deregulation of the ECS in many cancers has been extensively documented (Pacher et al., 2006; Alpini and Demorrow, 2009; Pisanti and Bifulco, 2009; Caffarel et al., 2012). Although there is a strong rationale for using $\mathrm{CB} 2 \mathrm{R}$ as an anti-cancer drug target (Guindon and Hohmann, 2011; Caffarel et al., 2012; Velasco et al., 2012), details on its impact in tumor development and progression is still lacking. The pro-oncogenic effect of $\mathrm{CB} 2 \mathrm{R}$ in HER2+ breast cancer was discovered when HER2-CB2R heteromers were detected in these cells, and having observed a simultaneous appearance of higher CB2 protein expression and poorer overall relapse-free and metastasis-free survival of patients (Pérez-Gómez et al., 2015). When there are no exogenous cannabinoids, CB2R regulates HER2 signaling (Pérez-Gómez et al., 2015), which was an unprecedented finding of CB2R-based control of HER2. Thus, strategies based on the simultaneous targeting of these two receptors (or their shared downstream effectors) may prove effective (Pérez-Gómez et al., 2015). It would potentially also mean that the combination of anti-HER2 drugs and cannabinoids acting on CB2R may induce synergistic anticancer effects. Recently, Blasco-Benito et al. (2019) proposed a mechanism controlling the oncogenic activity of HER2 in breast cancer through the HER2-CB2R heteromer. Inactivation and degradation of HER2 and promotion of antitumor responses is produced by the disruption of HER2-CB2R heteromer by THC, which binds selectively to CB2R, or by using a synthetic peptide with the amino acid sequence of specific transmembrane 5 domain (TM5) of the CB2R. All these findings reveal a new mechanism of regulation of HER2 activity, and support the existence HER2-CB2R heteromers as novel therapeutic targets for HER2+ breast cancer (Pérez-Gómez et al., 2015; Blasco-Benito et al., 2019).

The protein complexes CXCR4-CB2R, GPR55-CB2R and HER2-CB2R possess particular pharmacological and signaling properties, and their modulation might affect the antitumoral activity of the ECS. So, the cannabinoid receptor heteromers have a promising potential value as new targets for anti-cancer therapies and as prognostic biomarkers (Figure 2).

\section{Cannabinoid Ligands in Cancer}

The use of endocannabinoids as anti-cancer therapeutics has been extensively studied, and it can be concluded that they generally exert protective and beneficiary effects, inhibiting tumor growth and progression and restoring homeostasis. However, endocannabinoids are very important regulatory molecules involved in the metabolism of lipids and general signaling non-related to cancer, and there are reports that their levels can be elevated in some cancer subtypes (Zhang et al., 2016). So they also might also contribute to the pathogenesis and disease progression. Their interaction with standard chemo- and targeted therapies needs to be taken into account when exploring possible concurrent treatments, as they might interfere with the cytotoxic mechanisms in question (Miyato et al., 2009).

Since their discovery in the 1980s and 1990s, a lot of data has been published using various experimental models of cancer (from cell lines to genetically engineered mice) showing that various cannabinoids can have anti-tumor effects (Velasco et al., 2012). Endo- and exocannabinoids, as well as many synthetic cannabinoid receptor agonists have demonstrated this activity. Synthetic cannabinoids can have a comparable affinity for CBRs (WIN 55,212-2, HU-210), or higher affinity for one of them (methanandamide for CB1R, JWH-133 for $\mathrm{CB} 2 \mathrm{R}$ ). These findings add to the data load documenting that pharmacologic stimulation of CBRs is generally antitumorigenic. The induction of cancer cell death by apoptosis and the inhibition of proliferation is usually the mode of action of cannabinoids, in almost every tested cancer cell type (Velasco et al., 2012). Furthermore, it has been shown that cannabinoids reduce tumor angiogenesis as well as invasion/metastasis in vivo. However, there are also studies that document tumor-promoting effects of cannabinoids in vitro (Hart et al., 2004; Cudaback et al., 2010), and those that suggest that they diminish the immune system's ability to act as a tumor-suppressor (Zhu et al., 2000; McKallip et al., 2005). 


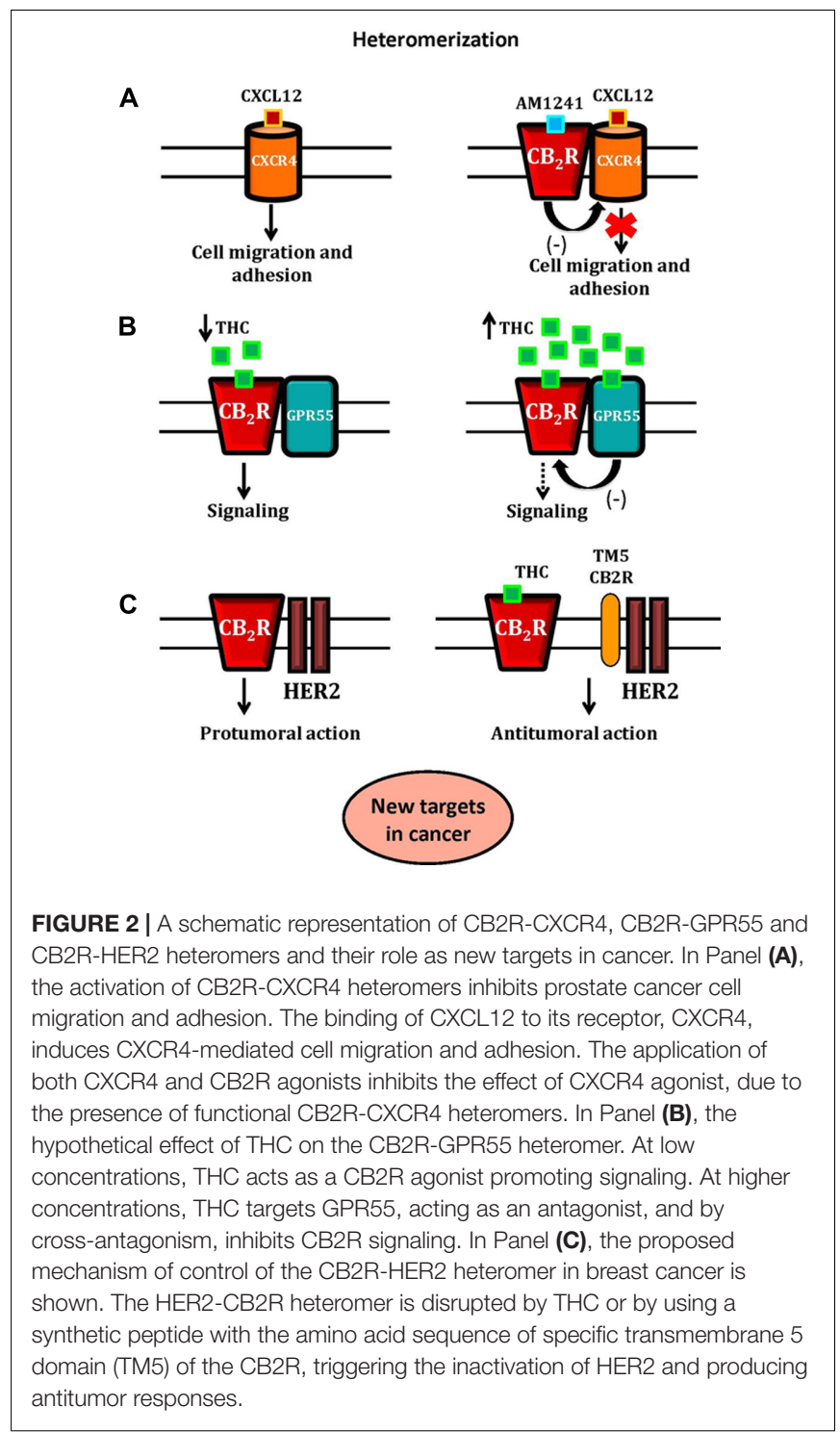

\section{Cannabinoid Enzymes and Transporters in Cancer}

Targeting ECS enzymes and transporters has also been explored as a therapeutic option with limited success, as any change in endocannabinoid biosynthesis, degradation and transport can have unpredictable effects in the organism. Changes in the endocannabinoid metabolic pathways by interfering with enzyme/transporter activity and levels can lead to an increased availability of endocannabinoids and general protective effects, especially in situations where these enzymes are deregulated as a consequence of tumorigenesis, as is the case with MAGL in colorectal cancer (Pagano et al., 2017). Many inhibitors of FAAH, MAGL and transporters are being tested in various experimental and clinical settings, alone and in combination (Ogawa and Kunugi, 2015; Panlilio et al., 2016; Chicca et al., 2017; Granchi et al., 2017), and many more are currently under development. However, a range of non-psychotropic CNS and systemic adverse effects needs to be thoroughly evaluated as learning and memory impairment can occur upon treatment (Panlilio et al., 2016).

\section{CANNABINOID-INDUCED ANTICANCER MECHANISMS}

\section{Cancer Cell Death}

Antiproliferative action of many plant-derived, endogenous and synthetic cannabinoids has been documented in various in vitro cancer models (Bifulco and Di Marzo, 2002; Guzmán, 2003). Also, in vivo experiments have confirmed that treatment of nude mice with cannabinoids leads to the formation of various tumor xenografts: lung carcinoma (Munson et al., 1975), thyroid epithelioma (Bifulco et al., 2001), lymphoma (McKallip et al., 2002), skin carcinoma (Casanova et al., 2003) and glioma (Galve-Roperh et al., 2000). Glioma cells have been used as the most common model system for studying cannabinoid-induced anticancer mechanisms. Initial studies showed that cannabinoids can induce apoptosis of glioma cells via CB1R and CB2R dependent de novo synthesis of the sphingolipid ceramide which has pro-apoptotic properties (Galve-Roperh et al., 2000; Sanchez et al., 2001; Gomez del Pulgar et al., 2002; Blázquez et al., 2004).

The level of cancer cell death resulting from the activation of CBRs depends on the type of agonist that evoked the response, and rarely on its mere affinity for a given CBR. For example, the synthetic agonist WIN-55,212-2 has a higher affinity for CBRs than THC, but lower concentrations of THC are needed for the comparable cancer cell death-inducing response (Pertwee et al., 2010). Beside the type of agonist, in some cases the type of receptor that is activated determines the resulting outcome. In glioma cells, the same level of inhibition of cannabinoid-induced cell death is achieved by antagonizing CB1R or CB2R, but in pancreatic, breast of hepatic cells only CB2R antagonists are effective (Galve-Roperh et al., 2000; Carracedo et al., 2006a; Caffarel et al., 2006; Lorente et al., 2011; Vara et al., 2011). The mechanisms which regulate these anti-cancer actions depending on agonist and receptor types are still unknown.

Autophagy has proven as one of the crucial effects of CBR agonists by which they promote cancer cell death. There are reports showing that activation of CBRs in vitro can lead to autophagy, and inhibition of autophagy via genetic or pharmacological mechanisms in vivo counteracts the anti-cancer effects of CBR agonists (Salazar et al., 2009; Vara et al., 2011). In various cancer types, the cannabinoidinduced autophagy is probably dependent on the p8 molecule, as its signaling is often upregulated upon cannabinoid treatment (Carracedo et al., 2006a,b; Salazar et al., 2009; Vara et al., 2011). Various other regulatory pathways are involved alongside with the p8-mediated autophagy, like an ER stress-dependent upregulation of AMPK coupled with TRIB3-induced downregulation of the AKT-mTORC1 pathway in hepatocellular carcinoma (Vara et al., 2011). In melanoma and breast cancer, activation of CBRs depends also on the 
downregulation of the AKT pathway (Blázquez et al., 2006; Caffarel et al., 2006), and in gliomas on the activation of TRPV2 receptors (Nabissi et al., 2012; Velasco et al., 2015). When hormone-dependent cancers are taken into account, cannabinoid agonists might also act through cooperation with growth factordependent pathways (Guzmán, 2003; Sarfaraz et al., 2008). Thus, the anti-cancer effects of cannabinoids are mediated by various mechanisms depending on the type of cancer cell in question, leading to an autophagy-mediated cell death (Guindon and Hohmann, 2011).

\section{Regulation of Cancer Angiogenesis and Local and Distant Invasion}

It has been reported that the vascular endothelial growth factor (VEGF)-induced cancer cell angiogenesis can be downregulated by the activation of CBRs in skin carcinomas (Casanova et al., 2003), gliomas (Blázquez et al., 2003, 2004) and thyroid carcinomas (Portella et al., 2003). Additionally, CB1R and/or CB2R agonists lead to an inhibition of adhesion and local and distant invasion in induced and spontaneous metastatic in vitro and in vivo models of glioma, breast, lung, and cervical cancer (Grimaldi et al., 2006; Blázquez et al., 2008; Preet et al., 2008; Ramer and Hinz, 2008; Qamri et al., 2009). Notably, it has been reported that when ceramide biosynthesis is inhibited in vitro or in vivo, the anti-cancer and anti-angiogenic effects of CBR activation are abolished (Blázquez et al., 2004).

It is also important to note that $\mathrm{CBD}$ acting through nonreceptor based mechanisms can generate a significant anti-cancer effect leading to a decrease of the invasive and metastatic potential in various animal cancer models (Velasco et al., 2015).

\section{Anticancer Immunity Regulation}

There are reports that ligand binding to CB2Rs can create a pro-tumorigenic surrounding by interfering with the immune system-mediated tumor surveillance mechanisms (Zhu et al., 2000; McKallip et al., 2005). On the other hand, cannabinoids have also been shown to enhance the tumor surveillance in melanoma xenografts in immunocompetent mice compared to immunodeficient mice, when using a synthetic cannabinoid WIN 55212-2 or JWH-133 (Blázquez et al., 2006; Velasco et al., 2015). Thus, the role of ECS is again dual depending on tumor type and the overall state of the immune system. Additionally, the formation of specific CBR homo- and heterooligomers upon stimulation with cannabinoids, and the subsequent change in their subcellular localization and coupling to $G$ proteins contributes to the complexity of this issue (Velasco et al., 2015).

\section{ETHICAL AND LEGAL ASPECTS OF USING ECS COMPONENTS IN ANTI-CANCER THERAPY}

As drug repurposing is significantly faster and more economical than de novo introduction of a new drug into the clinic, there is hope that the existing pharmacokinetic and safety data on various ECS components might contribute to their successful translation into oncological healthcare. However, many ethical and legal issues need to be addressed carefully especially before the use exogenous cannabinoids as anti-cancer drugs can become a reality. And while it appears that there are no obvious ethical and legal issues in targeting ECS enzymes/transporters or using endocannabinoids as anti-cancer drugs compared to the issues that exists with exogenous products, the matter of tumor-specificity and adverse effects of endogenous ECS-based approaches needs to be the main research objective.

\section{Ethical Dilemmas on Using Exogenous Cannabinoids in Medicine}

The debate over legalizing medical marijuana started heating up in the United States in the 1970, when the Controlled Substances Act was passed by the Congress. According to this Act, marijuana was listed as a schedule I drug which "has a high potential for abuse, no currently accepted medical use and lacks safety for use under medical supervision.” Being classified under the hallucinogenic substances category, the sale, purchase or consumption of marijuana became illegal.

The debate on whether marijuana can cause addiction and can seriously affect physiological state is still ongoing. Upon smoking cannabis, its active substances rapidly enter the blood stream and are quickly carried to the brain. With regular, heavy use, severe symptoms might arise such as depression, anxiety, irritability, bronchitis, conjunctivitis and endocrine disorders (Volkow et al., 2014). Although animal studies show that it can affect the immune system, there are no studies in humans that definitively correlate the immunosuppressive effects with either increased incidence of infections or immune disorders (Cabral and Staab, 2005). Short term cognitive effects include impairment of short term memory, sensory perception, attention span, problem solving, impaired motor coordination and psychomotor control, distorted judgment, and paranoia and psychosis in cases when higher doses are used (Volkow et al., 2014). It was shown that concurrent smoking of tobacco and marijuana synergistically increases the predisposition to respiratory problems and even chronic obstructive pulmonary disease (COPD). Smoking only marijuana cannot be directly associated with an increased risk of these problematic respiratory states (Tan et al., 2009).

The American Cancer Society (ACS) reported that marijuana's harmful substances are introduced into the body in a similar manner as tobacco consumption delivers cancer-causing substances. On the other hand, the ACS states that marijuana can alleviate suffering from pain when traditional medicine methods are exhausted. The ACS does not advocate the legalization of marijuana or its use, but they do support more research that would lead to exploitation of its benefits. Mixed reports on the causal relationship of chronic cannabis use and increased risk of cancer are showed in epidemiological literature (Hashibe et al., 2005). Hashibe et al. (2005) found that smoking cannabis was not associated with an increased risk of smoking-related cancers (e.g., lung, head, and neck), but might be associated with an increased risk of prostate cancer, cervical cancer, and glioma. Conversely, Reece reported that 
smoking cannabis is associated with an increased risk of lung cancer (Reece, 2009). Interestingly, Maertens et al. (2013) found that aside from the cannabinoids and nicotine, cannabis and tobacco smoke condensates contained mixtures that were similar. They also found that cannabis smoke condensate and tobacco smoke condensate influence the same molecular processes but have subtle pathway differences that potentially account for differential toxicities and the mixed results with respect to lung cancer. Even highly controversial, these potential hazards for the individuals seem to be good reasons to justify monitoring and to limit the access to the cannabis use. On the other hand, fear of legal consequences, ethical issues, social and legal barriers, stigma associated with abuse and lack of funding may interfere with the important research on the therapeutic potential of these controversial substances. These impediments could obstruct the research that might not just have the potential to alleviate chronic suffering and exploring harm reduction (Abrams, 1998) but might also have the potential to treat serious illnesses such as cancer.

While deciding on the policies, all harms and benefits of using cannabinoids should be taken into consideration. Also, the harms and benefits that are likely to result from the regulations that limit the access, use and the research on specific drugs must be taken into account. It is required that clinical trials minimize the risks for research subjects and to protect them from unreasonable risk. Reports documenting that cannabinoids reduce pain, nausea and spasms exist (Tramèr et al., 2001; Kalso, 2001), but it has also been argued that these medicinal benefits are overshadowed by the risks and the harmful side effects. There is also the argument of the lack of real need for its use in pain management since many other safer drugs are available (Kalso, 2001). To put more weight on the side of caution, legal and social risks must not be disregarded. Based on its unpopular and stigmatized use mostly in the Western countries, it seems that decisive clarity on whether benefits outweigh the risks of cannabinoid use for medical purposes will not be reached in the near future. When professionals' opinions are taken into consideration, it seems that the majority of medical doctors are in favor of medical marijuana use.

In this ongoing debate, the main arguments for allowing cannabis use come from the ideas of autonomy and freedom. Although the notion of autonomy has been used in many different relations, in biomedical ethics the idea of autonomy actually means self-government. The point of view that the value of patients' autonomy is more important than the value of protecting the patients' well-being highlights the bioethical issues that arise in the context of clinical research (Varelius, 2006). The definition of autonomy most often used in medical ethics is derived from the philosophy of Immanuel Kant who proposed that autonomy means personal self-determination. According to his doctrine, people can act "truly free" only if they act to their desires, attitudes or emotions. One could argue that cannabis use should not be forbidden to anyone, especially since there is a valid medical basis for its use. However, one could also argue that the use of psychoactive substances leads to addiction and clouds a person's judgment which seriously confronts the
Kantian model since addiction is prone to hinder self-determined decision making.

The formal bioethical principle of justice requires treating similar cases alike and different case differently. This concept also emphasizes fairness and equality among individuals. Since marijuana is listed as harmful and addictive and is banned as a class I drug, it can be stated that other harmful drugs as nicotine in the form of cigarettes and alcohol should be regarded alike and should not be allowed for use. The main question involving social justice can be formulated in the following manner: is it just to allow the research of substances that may alleviate conditions in one patient and prohibit or limit research on substances that might be the only ones that can help another patient? If the answer is yes, additional questions arise. When should such research be limited, why and by whom? Who is to decide about the fairness of the research? (Andreae et al., 2016). Respecting the autonomy and following the notion of social justice it does appear that marijuana should be legalized for medicinal use from the ethical point of view. Legalization of marijuana would be an example of utilitarianism if the positive outcome of such an action would outweigh the negative consequences. In case we consider drug use not only for symptoms alleviation but for the treatment of the disease itself, it seems that this risk/benefit calculation may be favorable in terms of greater benefits. While assessing physical risks we must not forget the psychological, social, legal risks and risks regarding privacy issues. Also, many risks vocalized through the media tend to be exaggerated and may distort our judgment of the real risks.

\section{Legalization Issues}

In June 2018, Canada made history by passing the Bill C-45 which is officially known as the Cannabis Act. By doing this, Canada has become the first industrialized nation in the world to have passed legislation allowing adults to purchase marijuana for recreational use. The only country in the world that has similar legislation so far is Uruguay. Per the Canadian law, adults over the age of 18 are allowed to purchase marijuana, as well as possess up to $30 \mathrm{~g}$ of dried cannabis for personal consumption (Canada Gov, 2018; CTV, 2018). Sale to minors is strictly prohibited.

Aside from Canada, USA's Vermont became the first US state to allow use of recreational cannabis entirely through the legislative process in the beginning of 2018. Meanwhile, Oklahoma passed legislation that legalized medical marijuana. Even though their approaches might be slightly different, 30 states in the United States allow marijuana for medical purpose ("Marijuana Is Legal for Medical Purposes in 32 States - Vox" 2018). This changing perception toward cannabis has been happening almost everywhere in the world and a growing number of countries have legalized medical marijuana to some extent. The use of marijuana in the medical setting has been fully legalized in Czechia. The Netherlands has also legalized its use and restricted it to "coffee shops", while outside of coffee shops, it is considered illegal (although decriminalized) to possess a maximum of $5 \mathrm{~g}$ or 5 plants. Poland, Romania, Norway, Germany, Italy, Greece have all legalized access for medical use. There are some European countries where cannabis is not legalized for smoking such as France, Spain and Slovenia but the 
use of cannabis-derived drugs is permitted. In Israel, Romania, Macedonia and Puerto Rico, marijuana use is illegal, but has been made available in cases of severe or terminal illnesses. Following the examples of Uruguay, nine states in the United States and most recently Canada, there have been many initiatives to propose legalizing cannabis in the more restrictive counties. For example, Spain has reignited the debate over legalizing marijuana. In Australia medical marijuana is legal at the federal level but the implementation is not the same in all states. In Victoria and New South Wales a cannabis card is necessary, and in the Australian Capital Territory and South Australia personal cultivation of up to two plants is allowed.

According to the UN survey (CNN, 2018) over 10,000 tons of cannabis is produced in the African continent each year and Africa appears to be the next large market for cannabis legalization. In May 2018, Zimbabwe legalized growing marijuana for medicinal and research purposes. Similarly, Lesotho began approving medical marijuana culturing licenses in 2017. The UN Office on Drugs and Crime reported that Morocco is the second-largest producer of cannabis in the world. Because of the huge potential that this industry could have on Morocco's economy, in 2014 the bill to legalize marijuana production for medical and industrial use was proposed in the Moroccan parliament. The bill failed at the time due to political and religious reasons and it seems that it will be difficult to overcome them any time soon.

\section{CLINICAL TRIALS}

Clinical trials have shown important findings investigating various components of the ECS (Table 2). FAAH is a membrane enzyme that degrades anandamide and is therefore a very attractive pharmacological target in many diseases. Many efforts have been employed to design and test new FAAH inhibitors or modulators of its activity (Lodola et al., 2015). However, the very unfavorable outcome of the French phase I study using the BIA 10-2474 FAAH inhibitor on healthy human volunteers is a dramatic example of how unpredictable the translation of ECS-based drugs into the clinic can be (Kaur et al., 2016). Currently, there are no approved FAAH inhibitors in clinical use, although the US FDA (in collaboration with the European Medicines Agency and the French national medicines agency) released a statement after the failure of this trial that other classes of FAAH inhibitors do not pose similar safety risks (FDA, 2016).

Because of its key role in the degradation of the 2-AG, targeting MAGL represents an interesting therapeutic target. In addition, MAGL is over-expressed in various cancers (breast, ovarian, melanoma) thus its inhibition can lead to a decrease of migration of cells and their invasiveness (Granchi et al., 2017). Also, MAGL controls the release of fatty acids from lipid-rich cancer cell compartments, which can lead to an activation of lipid signaling pathways implicated in migration, invasion, survival, and tumor growth. Thus, MAGL inhibitors have proven as promising candidates for anti-cancer therapy. Because of its specific properties, many compounds with a
MAGL inhibition activity were investigated by academia and pharmaceutical companies. MAGL inhibitors have been patented for a large number of therapeutic uses, mainly covering the area of pain and inflammation, metabolic disorders (such as obesity and diabetes), neurodegenerative pathologies (such as Alzheimer's disease), as well as the treatment of cancer, anxiety, and epilepsy (Granchi et al., 2017).

Following the example of Ben Amar who reviewed the existing clinical trials using cannabis and exogenous cannabinoids from 1975 to June 2005 (Ben Amar, 2006), two review papers were issued in 2010 and in 2014 reporting more recent clinical trial data. Both of these reviews were based on systematic research of PubMed for published randomized (double) blinded, placebo-controlled clinical trials, using the following keywords: cannabis, marijuana, marihuana, hashish, cannabinoid(s), tetrahydrocannabinol, THC, CBD, dronabinol, Marinol, nabilone, Cannador, nabiximols and Sativex.

In the review that covered period between 2006 and 2010, 37 such studies were identified (Hazekamp and Grotenhermen, 2010a), and 8 main indications of cannabinoid use were: neuropathic or chronic pain, experimental pain, multiple sclerosis and spasticity, HIV/AIDS, glaucoma, intestinal dysfunction, nausea/vomiting/appetite and schizophrenia. Based on the data presented in this study, cannabinoids showed most promise for the treatment of multiple sclerosis, but also as analgesics in chronic neuropathic pain and as appetite stimulants in cancer and AIDS. A wide range of cannabis-based drugs exhibited analgesic effects on various types of chronic and neuropathic pain with the majority of the adverse effects being mild or moderate, while they did not have such a prominent effect on acute types of pain.

One of the first studies performed to evaluate cannabinoid antitumoral action was performed by Guzmán and collaborators, who showed that cannabinoids can inhibit tumor growth (Guzmán, 2003). Due to the ethical and legal issues discussed previously, the first studies were conducted in terminal patients with recurrent tumors (Guzmán et al., 2006). These first trials shed the light not just on the palliative effects, but also on the possible antitumoral effects of cannabinoids, alone or in combination with other drugs as well.

In the review that covered the period between 2010 and 2014, 32 controlled studies were reported that further investigated the therapeutic potential of cannabinoids (Hazekamp and Grotenhermen, 2010b). Eleven main indications for which cannabinoids showed greatest treatment potential included: chronic pain, multiple sclerosis, irritable bowel syndrome, Crohn's disease, appetite and chemosensory perception, chemotherapy-induced nausea and vomiting, pulmonary diseases, cannabis dependence, psychosis and Parkinson's disease. Compared to the previous report period, the effect of oral cannabis on patients suffering from chronic pain was much more investigated, as there was an increase in the number of patients participating in pain-related clinical trials. Because of the various limitations of cannabinoid use in a clinical setting for most of the investigated conditions, chronic pain currently remains the major field of research interests as it is linked to less controversy while providing an acceptable benefit. 


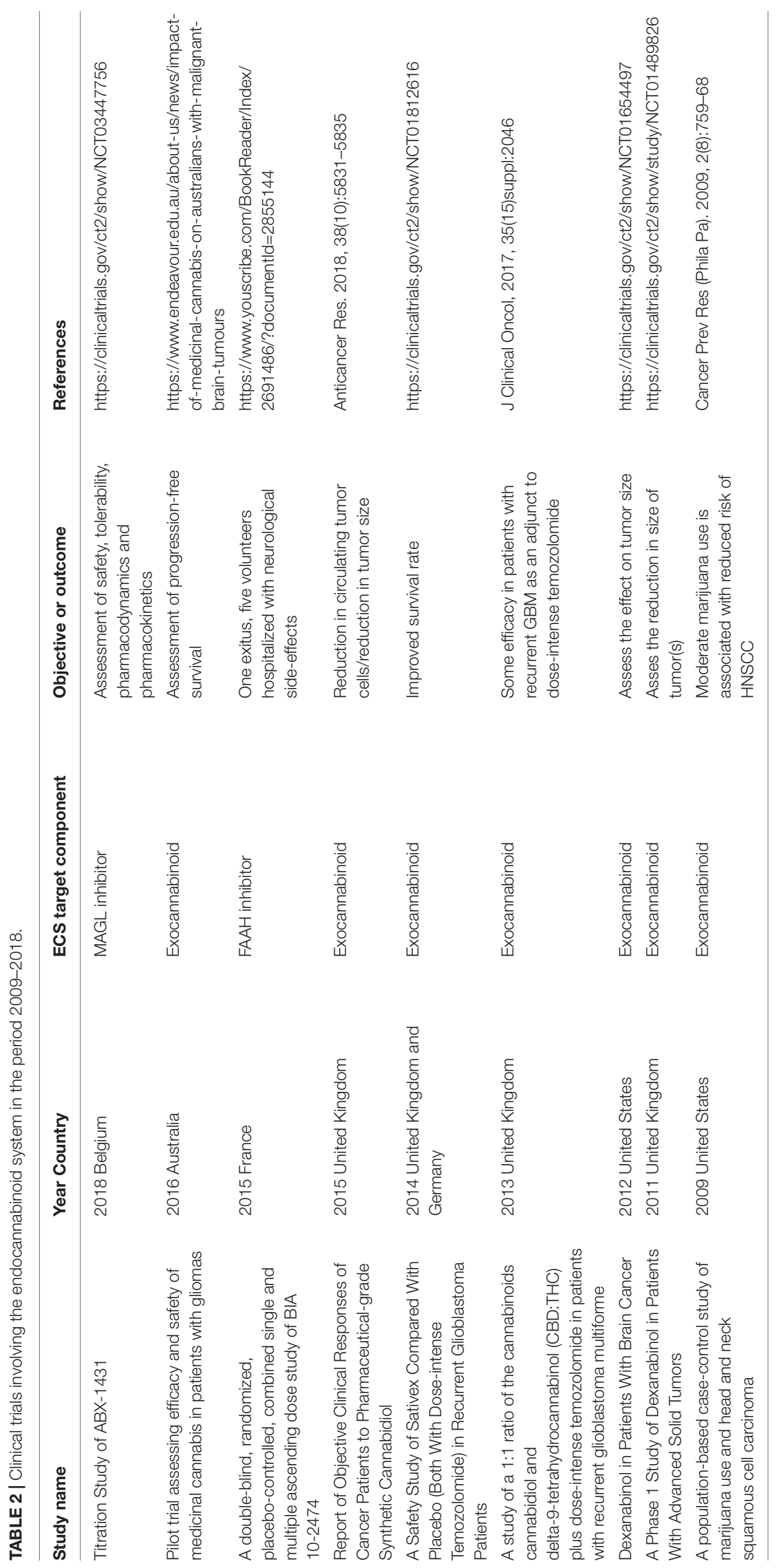


There are many review papers and meta-analyses discussing the safety, toxicology and therapeutic effects of exogenous cannabinoids. Out of the 70 known cannabinoids derived from the plant Cannabis sp., variety of synthetic cannabinoids and cannabinoid extracts, THC and CBD are the most commonly researched cannabinoids in the literature. Different methods of administration, inconsistent dosing measures, and highly variable cannabinoid content of cannabis plants only add to the already complex interactions of exogenous and endogenous cannabionids. Factors such as light, temperature, humidity, and soil type during cultivation, genetic factors, the method of administration (e.g., oral, smoked, vaporized) and form of cannabinoid consumed (e.g., stems and buds, hashish, hash oil, extract, synthetic) can impact the response to use. Since future clinical trials focusing on anticancer effects of cannabinoids will most likely not be conducted as monotherapy, research studies concerning probable interactions between cannabinoids and cytostatic drugs have shown promising effects. For example, THC and CBD enhance the cytotoxic impact of several chemotherapeutics such as cytarabine, doxorubicin, mitoxantrone, carmustine, temozolomide, bortezomib, carfilzomib and cisplatin (Ramer and Hinz, 2017). THC and CBD have been also shown to enhance the cytostatic effect of vinblastine in resistant leukemia cells and of mitoxantrone in embryonic fibroblasts (Holland et al., 2006, 2007). An enhancement of the cytostatic properties of cytarabine, doxorubicin and vincristine has, likewise, been substantiated for THC in leukemia cells (Liu et al., 2008). Synergistic actions were further reported for the effect of a CBD/THC combination added to multiple myeloma cells in the presence of carfilzomib. The susceptibility of glioblastoma cells for the cytotoxic action of cisplatin was found to be enhanced by CBD (Deng et al., 2017).

In 2017, phase II, randomized, placebo-controlled clinical trial with recurrent glioblastoma multiforme patients was announced and showed the potential efficacy of cannabinoids as add-on anticancer drugs. 12 patients were randomized to a combination of THC and CBD in addition to dose-intensive temozolomide, whereas 9 patients were randomized to placebo plus standard of care. This study showed a significantly higher one year survival rate in the cannabinoid group ( $83 \%$ vs. $53 \%$ ), and the median survival for the cannabinoid group was greater than 550 days comparing to 369 days in the placebo group (GW Pharmaceuticals, 2017 press release; ClinicalTrials.gov Identifiers: NCT01812616, NCT01812603).

\section{REFERENCES}

Abrams, D. I. (1998). Medical marijuana: tribulations and trials. J. Psychoactive Drugs 30, 163-169. doi: 10.1080/02791072.1998.10399686

Acharya, N., Penukonda, S., Shcheglova, T., Hagymasi, A. T., Basu, S., and Srivastava, P. K. (2017). Endocannabinoid system acts as a regulator of immune homeostasis in the gut. Proc. Natl. Acad. Sci. U.S.A. 114, 5005-5010. doi: 10. 1073/pnas.1612177114

Agnati, L., Fuxe, K., Zini, I., Lenzi, P., and Hökfelt, T. (1980). Aspects on receptor regulation and isoreceptor identification. Med. Biol. 58, $182-187$.

\section{FUTURE DIRECTIONS}

Although the ECS has been studied in detail by many research groups for decades, its clinical value as an anti-cancer target is still under debate. More intensive basic research is needed for a more precise characterization of the biochemical ECS mechanisms that are crucial in the cancer-setting, especially when cannabinoid-based/standard drug combinations are taken into account. Rigorous testing before any such drug should advance to phase-I clinical trials needs to be a matter of global consensus. Proper selection of target patient groups needs to be intensified to comply with all Good Clinical Practice regulations, as well as bioethical principles and legal boundaries, in order to achieve the right drug response in the right patient at the right moment.

\section{CONCLUSION}

There is an overwhelming burden of evidence that the ECS and all its components is an attractive anti-cancer target, but different strategies are yet to be rigorously clinically tested in order to exploit its full potential, such as explore the value of cannabinoid receptor heteromers as potential new targets for anti-cancer therapies and as prognostic biomarkers. Taking into account all the ethical issues involved in the use of ECS exogenous ligands in anti-cancer therapy and the number of ongoing clinical trials, we are definitely still not there yet, but the route is firm and sprinkled with hope for success.

\section{AUTHOR CONTRIBUTIONS}

All authors wrote the manuscript, contributed to manuscript revision, and read and approved the submitted version.

\section{FUNDING}

This work was supported by "Ministerio de Economía y Competitividad" and European Regional Development Funds of the European Union (Grant No. SAF2017-87629-R) and the Ministry of Education and Science of the Republic of Serbia (Grant No. III41026).

Agnati, L. F., Ferré, S., Genedani, S., Leo, G., Guidolin, D., Filaferro, M., et al. (2006). Allosteric modulation of dopamine D2 receptors by homocysteine. $J$ Proteome Res. 5, 3077-3083. doi: 10.1021/pr0601382

Agnati, L. F., Tarakanov, A. O., Ferré, S., Fuxe, K., and Guidolin, D. (2005). Receptor- interactions receptor, receptor mosaics, and basic principles of molecular network organization: possible implications for drug development. J. Mol. Neurosci. 26, 193-208. doi: 10.1385/JMN:26:2-3:193

Ahn, K. H., Mahmoud, M. M., Shim, J. Y., and Kendall, D. A. (2013). Distinct roles of $\beta$-arrestin 1 and $\beta$-arrestin 2 in ORG27569-induced biased signaling and internalization of the cannabinoid receptor 1 (CB1). J. Biol. Chem. 288, 9790-9800. doi: 10.1074/jbc.M112.438804 
Akgün, E., Javed, M. I., Lunzer, M. M., Smeester, B. A., Beitz, A. J., and Portoghese, P. S. (2013). Ligands that interact with putative MOR-mGluR5 heteromer in mice with inflammatory pain produce potent antinociception. Proc. Natl. Acad. Sci. U.S.A. 110, 11595-11599. doi: 10.1073/pnas.1305461110

Albizu, L., Cottet, M., Kralikova, M., Stoev, S., Seyer, R., Brabet, I., et al. (2010). Time-resolved FRET between GPCR ligands reveals oligomers in native tissues. Nat. Chem. Biol. 6, 587-594. doi: 10.1038/nchembio.396

Alpini, G., and Demorrow, S. (2009). Changes in the endocannabinoid system may give insight into new and effective treatments for cancer. Vitam. Horm. 81, 469-485. doi: 10.1016/S0083-6729(09)81018-2

Andradas, C., Caffarel, M. M., Pérez-Gómez, E., Salazar, M., Lorente, M., Velasco, G., et al. (2011). The orphan G protein coupled receptor GPR55 promotes cancer cell proliferation via ERK. Oncogene 30, 245-252. doi: 10.1038/ onc. 2010.402

Andreae, M. H., Rhodes, E., Bourgoise, T., Carter, G. M., White, R. S., Indyk, D., et al. (2016). An ethical exploration of barriers to research on controlled drugs. Am. J. Bioeth. 16, 36-47. doi: 10.1080/15265161.2016.1145282

Angers, S., Salahpour, A., and Bouvier, M. (2002). Dimerization: an emerging concept for G protein-coupled receptor ontogeny and function. Annu. Rev. Pharmacol. Toxicol. 42, 409-35. doi: 10.1146/annurev.pharmtox.42.091701. 082314

Angers, S., Salahpour, A., Joly, E., Hilairet, S., Chelsky, D., Dennis, M., et al. (2000). Detection of beta 2 -adrenergic receptor dimerization in living cells using bioluminescence resonance energy transfer (BRET). Proc. Natl. Acad. Sci. U.S.A. 97, 3684-3689. doi: 10.1073/pnas.060590697

Arcemisbéhère, L., Sen, T., Boudier, L., Balestre, M. N., Gaibelet, G., Detouillon, E., et al. (2010). Leukotriene BLT2 receptor monomers activate the G(i2) GTPbinding protein more efficiently than dimers. J. Biol. Chem. 285, 6337-6347. doi: 10.1074/jbc.M109.083477

Atwood, B. K., and Mackie, K. (2010). CB2: a cannabinoid receptor with an identity crisis. Br. J. Pharmacol. 160, 467-479. doi: 10.1111/j.1476-5381.2010.00729.x

Ayoub, M. A., Levoye, A., Delagrange, P., and Jockers, R. (2004). Preferential formation of MT1/MT2 melatonin receptor heterodimers with distinct ligand interaction properties compared with MT2 homodimers. Mol. Pharmacol. 66, 312-321. doi: 10.1124/mol.104.000398

Baba, K., Benleulmi-Chaachoua, A., Journé, A. S., Kamal, M., Guillaume, J. L., Dussaud, S., et al. (2013). Heteromeric MT1/MT2 melatonin receptors modulate photoreceptor function. Sci. Signal. 6:ra89. doi: 10.1126/scisignal. 2004302

Bagher, A. M., Laprairie, R. B., Toguri, J. T., Kelly, M. E. M., and DenovanWright, E. M. (2017). Bidirectional allosteric interactions between cannabinoid receptor $1\left(\mathrm{CB}_{1}\right)$ and dopamine receptor 2 long $\left(\mathrm{D}_{2 \mathrm{~L}}\right)$ heterotetramers. Eur. J. Pharmacol. 813, 66-83. doi: 10.1016/j.ejphar.2017.07.034

Balenga, N. A., Aflaki, E., Kargl, J., Platzer, W., Schröder, R., Blättermann, S., et al. (2011). GPR55 regulates cannabinoid 2 receptor-mediated responses in human neutrophils. Cell Res. 21, 1452-1469. doi: 10.1038/cr.2011.60

Balenga, N. A., Martínez-Pinilla, E., Kargl, J., Schröder, R., Peinhaupt, M., Platzer, W., et al. (2014). Heteromerization of GPR55 and cannabinoid CB2 receptors modulates signalling. Br. J. Pharmacol. 171, 5387-5406. doi: 10.1111/ bph. 12850

Baltoumas, F. A., Theodoropoulou, M. C., and Hamodrakas, S. J. (2016). Molecular dynamics simulations and structure-based network analysis reveal structural and functional aspects of G-protein coupled receptor dimer interactions. J. Comput. Aided Mol. Des. 6, 489-512. doi: 10.1007/s10822-016-9919-y

Bauer, M., Chicca, A., Tamborrini, M., Eisen, D., Lerner, R., Lutz, B., et al. (2012). Identification and quantification of a new family of peptide endocannabinoids (Pepcans) showing negative allosteric modulation at $\mathrm{CB}_{1}$ receptors. J. Biol. Chem. 287, 36944-36967. doi: 10.1074/jbc.M112.382481

Bayburt, T. H., Vishnivetskiy, S. A., McLean, M. A., Morizumi, T., Huang, C. C., Tesmer, J. J., et al. (2011). Monomeric rhodopsin is sufficient for normal rhodopsin kinase (GRK1) phosphorylation and arrestin-1 binding. J. Biol. Chem. 286, 1420-1428. doi: 10.1074/jbc.M110.151043

Bellot, M., Galandrin, S., Boularan, C., Matthies, H. J., Despas, F., Denis, C., et al. (2015). Dual agonist occupancy of AT1-R- $\alpha 2 C-A R$ heterodimers results in atypical Gs-PKA signaling. Nat. Chem. Biol. 11, 271-279. doi: 10.1038/ nchembio. 1766

Ben Amar, M. (2006). Cannabinoids in medicine: a review of their therapeutic potential. J. Ethnopharmacol. 105, 1-25. doi: 10.1016/j.jep.2006. 02.001
Bifulco, M., and Di Marzo, V. (2002). Targeting the endocannabinoid system in cancer therapy: a call for further research. Nat. Med. 8, 547-550. doi: 10.1038/ nm0602-547

Bifulco, M., Laezza, C., Portella, G., Vitale, M., Orlando, P., De Petrocellis, L., et al. (2001). Control by the endogenous cannabinoid system of ras oncogenedependent tumor growth. FASEB J. 15, 2745-2747. doi: 10.1096/fj.01-0320fje

Bisogno, T., Hanus, L., De Petrocellis, L., Tchilibon, S., Ponde, D. E., Brandi, I., et al. (2001). Molecular targets for cannabidiol and its synthetic analogues: effect on vanilloid VR1 receptors and on the cellular uptake and enzymatic hydrolysis of anandamide. Br. J. Pharmacol. 134, 845-852. doi: 10.1038/sj.bjp.0704327

Blasco-Benito, S., Moreno, E., Seijo-Vila, M., Tundidor, I., Andradas, C., Caffarel, M. M., et al. (2019). Therapeutic targeting of HER2-CB2R heteromers in HER2-positive breast cancer. Proc. Natl. Acad. Sci. U.S.A. 116, 3863-3872. doi: $10.1073 /$ pnas. 1815034116

Blázquez, C., Carracedo, A., Barrado, L., Real, P. J., Fernandez-Luna, J. L., Velasco, G., et al. (2006). Cannabinoid receptors as novel targets for the treatment of melanoma. FASEB J. 20, 2633-2635. doi: 10.1096/fj.06-6638fje

Blázquez, C., Casanova, M. L., Planas, A., Gomez del Pulgar, T., Villanueva, C., Fernandez-Acenero, M. J., et al. (2003). Inhibition of tumor angiogenesis by cannabinoids. FASEB J. 17, 529-531. doi: 10.1096/fj.02-0795fje

Blázquez, C., Gonzalez-Feria, L., Alvarez, L., Haro, A., Casanova, M. L., and Guzmán, M. (2004). Cannabinoids inhibit the vascular endothelial growth factor pathway in gliomas. Cancer Res. 64, 5617-5623. doi: 10.1158/0008-5472. CAN-03-3927

Blázquez, C., Salazar, M., Carracedo, A., Lorente, M., Egia, A., GonzalezFeria, L., et al. (2008). Cannabinoids inhibit glioma cell invasion by downregulating matrix metalloproteinase-2 expression. Cancer Res. 68, 1945-1952. doi: 10.1158/0008-5472.CAN-07-5176

Bonaventura, J., Navarro, G., Casadó-Anguera, V., Azdad, K., Rea, W., Moreno, E., et al. (2015). Allosteric interactions between agonists and antagonists within the adenosine A2A receptor-dopamine D2 receptor heterotetramer. Proc. Natl. Acad. Sci. U.S.A. 112, E3609-E3618. doi: 10.1073/pnas.1507704112

Bonaventura, J., Rico, A. J., Moreno, E., Sierra, S., Sánchez, M., Luquin, N., et al. (2014). L-DOPA-treatment in primates disrupts the expression of A (2A) adenosine-CB (1) cannabinoid-D(2) dopamine receptor heteromers in the caudate nucleus. Neuropharmacology 79, 90-100. doi: 10.1016/j.neuropharm. 2013.10.036

Borroto-Escuela, D. O., Rodriguez, D., Romero-Fernandez, W., Kapla, J., Jaiteh, M., Ranganathan, A., et al. (2018). Mapping the interface of a GPCR dimer: a structural model of the A2A adenosine and D2 dopamine receptor heteromer. Front. Pharmacol. 9:829. doi: 10.3389/fphar.2018.00829

Borroto-Escuela, D. O., Romero-Fernandez, W., Mudó, G., Pérez-Alea, M., Ciruela, F., Tarakanov, A. O., et al. (2012). Fibroblast growth factor receptor 15- hydroxytryptamine 1A heteroreceptor complexes and their enhancement of hippocampal plasticity. Biol. Psychiatry 71, 84-91. doi: 10.1016/j.biopsych.2011. 09.012

Cabral, G. A., and Staab, A. (2005). Effects on the immune system. Handb. Exp. Pharmacol. 168, 385-423. doi: 10.1007/3-540-26573-2_13

Caffarel, M. M., Andradas, C., Mira, E., Pérez-Gómez, E., Cerutti, C., MorenoBueno, G., et al. (2010). Cannabinoids reduce ErbB2-driven breast cancer progression through Akt inhibition. Mol. Cancer 9:196. doi: 10.1186/14764598-9-196

Caffarel, M. M., Andradas, C., Perez-Gomez, E., Guzmán, M., and Sánchez, C. (2012). Cannabinoids: a new hope for breast cancer therapy? Cancer Treat. Rev. 38, 911-998. doi: 10.1016/j.ctrv.2012.06.005

Caffarel, M. M., Sarrio, D., Palacios, J., Guzmán, M., and Sanchez, C. (2006). Delta9-tetrahydrocannabinol inhibits cell cycle progression in human breast cancer cells through Cdc2 regulation. Cancer Res. 66, 6615-6621. doi: 10.1158/ 0008-5472.CAN-05-4566

Cai, Y., Liu, Y., Culhane, K., DeVree, B. T., Yang, Y., Sunahara, R. K., et al. (2017). Purification of family B G protein-coupled receptors using nanodiscs: application to human glucagon-like peptide-1 receptor. PLoS One 12:e179568. doi: 10.1371/journal.pone.0179568

Calebiro, D., Rieken, F., Wagner, J., Sungkaworn, T., Zabel, U., Borzi, A., et al. (2013). Single-molecule analysis of fluorescently labeled G-protein coupled receptors reveals complexes with distinct dynamics and organization. Proc. Natl. Acad. Sci. U.S.A. 110, 743-748. doi: 10.1073/pnas.1205798110

Calebiro, D., and Sungkaworn, T. (2018). Single-molecule imaging of GPCR interactions. Trends Pharmacol. Sci. 39, 109-122. doi: 10.1016/j.tips.2017.10.010 
Callén, L., Moreno, E., Barroso-Chinea, P., Moreno-Delgado, D., Cortés, A., Mallol, J., et al. (2012). Cannabinoid receptors CB1 and CB2 form functional heteromers in brain. J. Biol. Chem. 287, 20851-20865. doi: 10.1074/jbc.M111. 335273

Canada Gov (2018). Bill C-45, the Cannabis Act, Passed in Senate Canada.ca. Available at: https://www.canada.ca/en/health-canada/news/2018/ 06/bill-c-45-the-cannabis-act-passed-in-senate.html (accessed December 13, 2018).

Carracedo, A., Gironella, M., Lorente, M., Garcia, S., Guzmán, M., Velasco, G. et al. (2006a). Cannabinoids induce apoptosis of pancreatic tumor cells via endoplasmic reticulum stress-related genes. Cancer Res. 66, 6748-6755. doi: 10.1158/0008-5472.CAN-06-0169

Carracedo, A., Lorente, M., Egia, A., Blazquez, C., Garcia, S., Giroux, V., et al. (2006b). The stress-regulated protein p8 mediates cannabinoid-induced apoptosis of tumor cells. Cancer Cell 9, 301-312. doi: 10.1016/j.ccr.2006.03.005

Carriba, P., Navarro, G., Ciruela, F., Ferré, S., Casadó, V., Agnati, L., et al. (2008). Detection of heteromerization of more than two proteins by sequential BRET-FRET. Nat. Methods 5, 727-733. doi: 10.1038/nmeth.1229

Carriba, P., Ortiz, O., Patkar, K., Justinova, Z., Stroik, J., Themann, A., et al. (2007). Striatal adenosine A2A and cannabinoid CB1 receptors form functional heteromeric complexes that mediate the motor effects of cannabinoids. Neuropsychopharmacology 32, 2249-2259. doi: 10.1038/sj.npp.1301375

Casadó-Anguera, V., Bonaventura, J., Moreno, E., Navarro, G., Cortés, A., Ferré, S., et al. (2016). Evidence for the heterotetrameric structure of the adenosine A2A-dopamine D2 receptor complex. Biochem. Soc. Trans. 44, 595-600. doi: 10.1042/BST20150276

Casanova, M. L., Blázquez, C., Martínez-Palacio, J., Villanueva, C., FernándezAceñero, M. J., Huffman, J. W., et al. (2003). Inhibition of skin tumor growth and angiogenesis in vivo by activation of cannabinoid receptors. J. Clin. Invest. 111, 43-50. doi: 10.1172/JCI16116

Cervetto, C., Venturini, A., Guidolin, D., Maura, G., Passalacqua, M., Tacchetti, C., et al. (2018). Homocysteine and A2A-D2 receptor-receptor interaction at striatal astrocyte processes. J. Mol. Neurosci. 65, 456-466. doi: 10.1007/s12031018-1120-4

Chabre, M., and le Maire, M. (2005). Monomeric G-protein coupled receptor as a funcional unit. Biochemistry 44, 9395-9403. doi: 10.1021/bi050720o

Chicca, A., Nicolussi, S., Bartholomaus, R., Blunder, M., Aparisi Rey, A., Petrucci, V., et al. (2017). Chemical probes to potently and selectively inhibit endocannabinoid cellular reuptake. Proc. Natl. Acad. Sci. U.S.A. 114, E5006E5015. doi: 10.1073/pnas.1704065114

Cianchi, F., Papucci, L., Schiavone, N., Lulli, M., Magnelli, L., Vinci, M. C., et al. (2008). Cannabinoid receptor activation induces apoptosis through tumor necrosis factor alpha-mediated ceramide de novo synthesis in colon cancer cells. Clin. Cancer Res. 14, 7691-7700. doi: 10.1158/1078-0432.CCR-08-0799

CNN (2018). Africa's Weed Race? Zimbabwe Second Country to Legalize Medicinal Marijuana - CNN. Available at: https://edition.cnn.com/2017/10/09/ africa/african-countries-legalize-marijuana/index.html (accessed December 13, 2018)

Coke, C. J., Scarlett, K. A., Chetram, M. A., Jones, K. J., Sandifer, B. J., Davis, A. S., et al. (2016). Simultaneous activation of induced heterodimerization between CXCR4 chemokine receptor and cannabinoid receptor 2 (CB2) reveals a mechanism for regulation of tumor progression. J. Biol. Chem. 291, 9991-10005. doi: 10.1074/jbc.M115.712661

Conn, P. J., Christopoulos, A., and Lindsley, C. W. (2009). Allosteric modulators of GPCRs: a novel approach for the treatment of CNS disorders. Nat. Rev. Drug Discov. 8, 41-54. doi: 10.1038/nrd2760

Cortés, A., Moreno, E., Rodríguez-Ruiz, M., Canela, E. I., and Casadó, V. (2016). Targeting the dopamine D3 receptor: an overview of drug design strategies. Expert Opin. Drug Discov. 11, 641-664. doi: 10.1080/17460441.2016.1185413

CTV (2018). Timeline of Key Events in Marijuana Bill's Passage through Parliament | CTV News. Available at: https://www.ctvnews.ca/politics/timeline-of-keyevents-in-marijuana-bill-s-passage-through-parliament-1.3958662 (accessed December 13, 2018).

Cudaback, E., Marrs, W., Moeller, T., and Stella, N. (2010). The expression level of $\mathrm{CB} 1$ and $\mathrm{CB} 2$ receptors determines their efficacy at inducing apoptosis in astrocytomas. PLoS One 5:e8702. doi: 10.1371/journal.pone.0008702

Curtis, C., Shah, S. P., Chin, S. F., Turashvili, G., Rueda, O. M., Dunning, M. J., et al. (2012). The genomic and transcriptomic architecture of 2,000 breast tumours reveals novel subgroups. Nature 486, 346-352. doi: 10.1038/nature10983
Cvejic, S., and Devi, L. A. (1997). Dimerization of the delta opioid receptor: implication for a role in receptor internalization. J. Biol. Chem. 272, 26959-26964.

Cvicek, V., Goddard, W. A., and Abrol, R. (2016). Structure-based sequence alignment of the transmembrane domains of all human GPCRs: phylogenetic, structural and functional implications. PLoS Comput. Biol. 12:e1004805. doi: 10.1371/journal.pcbi.1004805

De Petrocellis, L., Melck, D., Bisogno, T., Milone, A., and Di Marzo, V. (1999). Finding of the endocannabinoid signalling system in Hydra, a very primitive organism: possible role in the feeding response. Neuroscience 92, 377-387. doi: 10.1016/S0306-4522(98)00749-0

Deng, L., Ng, L., Ozawa, T., and Stella, N. (2017). Quantitative analyses of synergistic responses between cannabidiol and DNA-damaging agents on the proliferation and viability of glioblastoma and neural progenitor cells in culture. J. Pharmacol. Exp. Ther. 360, 215-224. doi: 10.1124/jpet.116.236968

Devane, W. A., Dysarz, F. A. III, Johnson, M. R., Melvin, L. S., and Howlett, A. C. (1988). Determination and characterization of a cannabinoid receptor in rat brain. Mol. Pharmacol. 34, 605-613.

Devane, W. A., Hanus, L., Breuer, A., Pertwee, R. G., Stevenson, L. A., Griffin, G., et al. (1992). Isolation and structure of a brain constituent that binds to the cannabinoid receptor. Science 258, 1946-1949. doi: 10.1126/science.1470919

Di Pizio, A., Levit, A., Slutzki, M., Behrens, M., Karaman, R., and Niv, M. Y. (2016). Comparing class A GPCRs to bitter taste receptors: structural motifs, ligand interactions and agonist-to-antagonist ratios. Methods Cell Biol. 132, 401-427. doi: 10.1016/bs.mcb.2015.10.005

Di Scala, C., Fantini, J., Yahi, N., Barrantes, F. J., and Chahinian, H. (2018). Anandamide revisited: how cholesterol and ceramides control receptordependent and receptor-independent signal transmission pathways of a lipid neurotransmitter. Biomolecules 8:E31. doi: 10.3390/biom8020031

Dopart, R., Lu, D., Lichtman, A. H., and Kendall, D. A. (2018). Allosteric modulators of cannabinoid receptor 1: developing compounds for improved specificity. Drug Metab. Rev. 50, 3-13. doi: 10.1080/03602532.2018.1428342

Dyall, S. C. (2017). Interplay between n-3 and n-6 long-chain polyunsaturated fatty acids and the endocannabinoid system in brain protection and repair. Lipids 52, 885-900. doi: 10.1007/s11745-017-4292-8

Ellis, J., Pediani, J. D., Canals, M., Milasta, S., and Milligan, G. (2006). Orexin-1 receptor-cannabinoid $\mathrm{CB} 1$ receptor heterodimerization results in both liganddependent and -independent coordinated alterations of receptor localization and function. J. Biol. Chem. 281, 38812-38824. doi: 10.1074/jbc.M602494200

Ernst, O. P., Gramse, V., Kolbe, M., Hofmann, K. P., and Heck, M. (2007). Monomeric $\mathrm{G}$ protein-coupled receptor rhodopsin in solution activates its $\mathrm{G}$ protein transducin at the diffusion limit. Proc. Natl. Acad. Sci. U.S.A. 104, 10859-10864. doi: 10.1073/pnas.0701967104

Farran, B. (2017). An update on the physiological and therapeutic relevance of GPCR oligomers. Pharmacol. Res. 117, 303-327. doi: 10.1016/j.phrs.2017. 01.008

Fay, J. F., and Farrens, D. L. (2013). The membrane proximal region of the cannabinoid receptor CB1 N-terminus can allosterically modulate ligand affinity. Biochemistry 52, 8286-8294. doi: 10.1021/bi400842k

FDA (2016). FDA Finds Drugs Under Investigation in the U.S. Related to French BIA 10-2474 Drug do Not Pose Similar Safety Risks. Available at: https://www. fda.gov/Drugs/DrugSafety/ucm482740.htm (accessed December 25, 2018).

Feng, Z., Hu, G., Ma, S., and Xie, X. Q. (2015). Computational advances for the development of allosteric modulators and bitopic ligands in $G$ protein-coupled receptors. AAPS J. 17, 1080-1095. doi: 10.1208/s12248-0159776-y

Fernandez-Ruiz, J., Romero, J., Velasco, G., Tolón, R. M., Ramos, J. A., and Guzmán, M. (2007). Cannabinoid CB2 receptor: a new target for controlling neural cell survival? Trends Pharmacol. Sci. 28, 39-45. doi: 10.1016/j.tips.2006. 11.001

Ferré, S. (2015). The GPCR heterotetramer: challenging classical pharmacology. Trends Pharmacol. Sci. 36, 145-152. doi: 10.1016/j.tips.2015.01.002

Ferré, S., Baler, R., Bouvier, M., Caron, M. G., Devi, L. A., Durroux, T., et al. (2009). Building a new conceptual framework for receptor heteromers. Nat. Chem. Biol. 5, 131-134. doi: 10.1038/nchembio0309-131

Ferré, S., Casadó, V., Devi, L. A., Filizola, M., Jockers, R., and Lohse, M. J. (2014). G protein-coupled receptor oligomerization revisited: funcional and pharmacological perspectives. Pharmacol. Rev. 66, 413-434. doi: 10.1124/pr. 113.008052 
Flajolet, M., Wang, Z., Futter, M., Shen, W., Nuangchamnong, N., Bendor, J., et al. (2008). FGF acts as a co-transmitter through adenosine $\mathrm{A}(2 \mathrm{~A})$ receptor to regulate synaptic plasticity. Nat. Neurosci. 11, 1402-1409. doi: 10.1038/nn.2216

Foster, D. J., and Conn, P. J. (2017). Allosteric modulation of GPCRs: new insights and potential utility for treatment of schizophrenia and other CNS disorders. Neuron 94, 431-446. doi: 10.1016/j.neuron.2017.03.016

Fotiadis, D., Liang, Y., Filipek, S., Saperstein, D. A., Engel, A., and Palczewski, K. (2003). Atomic-force microscopy: rhodopsin dimers in native disc membranes. Nature 421, 127-128. doi: 10.1038/421127a

Franco, R., Martínez-Pinilla, E., Lanciego, J. L., and Navarro, G. (2016). Basic pharmacological and structural evidence for class A G-protein-coupled receptor heteromerization. Front. Pharmacol. 7:76. doi: 10.3389/fphar.2016. 00076

Fredriksson, R., Lagerström, M. C., Lundin, L. G., and Schiöth, H. B. (2003). The G-protein-coupled receptors in the human genome form five main families. Phylogenetic analysis, paralogon groups, and fingerprints. Mol. Pharmacol. 63, 1256-1272. doi: 10.1124/mol.63.6.1256

Fujita, W., Gomes, I., and Devi, L. A. (2015). Heteromers of $\mu-\delta$ opioid receptors: new pharmacology and novel therapeutic possibilities. Br. J. Pharmacol. 172, 375-387. doi: 10.1111/bph.12663

Fung, J. J., Deupi, X., Pardo, L., Yao, X. J., Velez-Ruiz, G. A., Devree, B. T., et al. (2009). Ligand-regulated oligomerization of beta(2)-adrenoceptors in a model lipid bilayer. EMBO J. 28, 3315-3328. doi: 10.1038/emboj.2009.267

Fuxe, K., Agnati, L., Benfenati, F., Cimmino, M., Algeri, S., Hökfelt, T., et al. (1981). Modulation by cholecystokinin of $[3 \mathrm{H}]$-spiroperidol binding in rat striatum: evidence for increased affinity and reduction in the number of binding sites. Acta Physiol. Scand. 113, 567-569. doi: 10.1111/j.1748-1716.1981.tb06942.x

Fuxe, K., and Agnati, L. F. (1985). Receptor-receptor interactions in the central nervous system. A new integrative mechanism in synapses. Med. Res. Rev. 5, 441-482. doi: 10.1111/j.1748-1716.1981.tb06942.x

Fuxe, K., Canals, M., Torvinen, M., Marcellino, D., Terasmaa, A., Genedani, S., et al. (2007). Intramembrane receptor-receptor interactions: a novel principle in molecular medicine. J. Neural Transm. 114, 49-75. doi: 10.1007/s00702-0060589-0

Gahbauer, S., and Böckmann, R. A. (2016). Membrane-mediated oligomerization of G protein coupled receptors and its implications for GPCR function. Front. Physiol. 7:494. doi: 10.3389/fphys.2016.00494

Gaitonde, S. A., and González-Maeso, J. (2017). Contribution of heteromerization to $G$ protein-coupled receptor function. Curr. Opin. Pharmacol. 32, 23-31. doi: 10.1016/j.coph.2016.10.006

Galve-Roperh, I., Sánchez, C., Cortés, M., Gómez del Pulgar, T., Izquierdo, M., and Guzmán, M. (2000). Antitumoral action of cannabinoids: involvement of sustained ceramide accumulation and extracellular signal-regulated kinase activation. Nat. Med. 6, 313-319. doi: 10.1038/73171

Glass, M., and Felder, C. C. (1997). Concurrent stimulation of cannabinoid CB1 and dopamine D2 receptors augments CAMP accumulation in striatal neurons: evidence for a Gs linkage to the CB1 receptor. J. Neurosci. 17, 5327-5333. doi: 10.1523/JNEUROSCI.17-14-05327.1997

Goin, J. C., and Nathanson, N. M. (2006). Quantitative analysis of muscarinic acetylcholine receptor homo- and heterodimerization in live cells: regulation of receptor down-regulation by heterodimerization. J. Biol. Chem. 281, 5416-5425. doi: 10.1074/jbc.M507476200

Gomes, I., Ayoub, M. A., Fujita, W., Jaeger, W. C., Pfleger, K. D. G., Devi, L. A., et al. (2016a). G protein- coupled receptor heteromers. Annu. Rev. Pharmacol. Toxicol. 56, 403-425. doi: 10.1146/annurev-pharmtox-011613-135952

Gomes, I., Sierra, S., and Devi, L. A. (2016b). Detection of receptor heteromerization using in situ proximity ligation assay. Curr. Protoc. Pharmacol. 75, 2.16.1-2.16.31. doi: 10.1002/cpph.15

Gomes, I., Gupta, A., and Devi, L. A. (2013a). G-protein-coupled heteromers: regulation in disease. Methods Enzymol. 521, 219-238. doi: 10.1016/B978-0-12391862-8.00012-0

Gomes, I., Fujita, W., Chandrakala, M. V., and Devi, L. A. (2013b). Disease-specific heteromerization of G-protein-coupled receptors that target drugs of abuse. Prog. Mol. Biol. Transl. Sci. 117, 207-265. doi: 10.1016/B978-0-12-386931-9. 00009-X

Gomes, I., Fujita, W., Gupta, A., Saldanha, S. A., Negri, A., Pinello, C. E., et al. (2013c). Identification of a $\mu-ð$ opioid receptor heteromer-biased agonist with antinociceptive activity. Proc. Natl. Acad. Sci. U.S.A. 110, 12072-12077. doi: $10.1073 /$ pnas. 1222044110

Gomes, I., Ijzerman, A. P., Ye, K., Maillet, E. L., and Devi, L. A. (2011). G proteincoupled receptor heteromerization: a role in allosteric modulation of ligand binding. Mol. Pharmacol. 79, 1044-1052. doi: 10.1124/mol.110.070847

Gomez del Pulgar, T., Velasco, G., Sanchez, C., Haro, A., and Guzmán, M. (2002). De novo-synthesized ceramide is involved in cannabinoid-induced apoptosis. Biochem. J. 363, 183-188. doi: 10.1042/bj3630183

González, A., Cordomí, A., Matsoukas, M., Zachmann, J., and Pardo, L. (2014). Modeling of $G$ protein-coupled receptors using crystal structures: from monomers to signaling complexes. Adv. Exp. Med. Biol. 796, 15-33. doi: 10. 1007/978-94-007-7423-0_2

González, S., Rangel-Barajas, C., Peper, M., Lorenzo, R., Moreno, E., Ciruela, F., et al. (2012). Dopamine D4 receptor, but not the ADHD-associated D4.7 variant, forms functional heteromers with the dopamine D2S receptor in the brain. Mol. Psychiatry 17, 650-662. doi: 10.1038/mp.2011.93

Gracia, E., Moreno, E., Cortés, A., Lluís, C., Mallol, J., McCormick, P. J., et al. (2013). Homodimerization of adenosine A1 receptors in brain cortex explains the biphasic effects of caffeine. Neuropharmacology 71, 56-69. doi: 10.1016/j. neuropharm.2013.03.005

Gracia, E., Pérez-Capote, K., Moreno, E., Barkešová, J., Mallol, J., Lluís, C., et al. (2011). A2A adenosine receptor ligand binding and signalling is allosterically modulated by adenosine deaminase. Biochem. J. 435, 701-709. doi: 10.1042/ BJ20101749

Granchi, C., Caligiuri, I., Minutolo, F., Rizzolio, F., and Tuccinardi, T. (2017). A patent review of monoacylglycerol lipase (MAGL) inhibitors (2013-2017). Expert Opin. Ther. Pat. 27, 1341-1351. doi: 10.1080/13543776.2018.1389899

Grimaldi, C., Pisanti, S., Laezza, C., Malfitano, A. M., Santoro, A., Vitale, M., et al. (2006). Anandamide inhibits adhesion and migration of breast cancer cells. Exp. Cell Res. 312, 363-373. doi: 10.1016/j.yexcr.2005.10.024

Guidolin, D., Marcoli, M., Tortorella, C., Maura, G., and Agnati, L. F. (2018). $\mathrm{G}$ protein-coupled receptor-receptor interactions give integrative dynamics to intercellular communication. Rev. Neurosci. 29, 703-726. doi: 10.1515/ revneuro-2017-0087

Guindon, J., and Hohmann, A. G. (2011). The endocannabinoid system and cancer: therapeutic implication. Br. J. Pharmacol. 163, 1447-1463. doi: 10.1111/j.14765381.2011.01327.x

Guitart, X., Navarro, G., Moreno, E., Yano, H., Cai, N. S., Sánchez-Soto, M., et al. (2014). Functional selectivity of allosteric interactions within G proteincoupled receptor oligomers: the dopamine D1-D3 receptor heterotetramer. Mol. Pharmacol. 86, 417-429. doi: 10.1124/mol.114.093096

Gupta, A., Mulder, J., Gomes, I., Rozenfeld, R., Bushlin, I., Ong, E., et al. (2010). Increased abundance of opioid receptor heteromers after chronic morphine administration. Sci. Signal. 3:ra54. doi: 10.1126/scisignal.2000807

Gurevich, V. V., and Gurevich, E. V. (2017). Molecular mechanisms of GPCR signaling: a structural perspective. Int. J. Mol. Sci. 18:e2519. doi: 10.3390/ ijms18122519

Guzmán, M. (2003). Cannabinoids: potential anticancer agents. Nat. Rev. Cancer 3, 745-755. doi: 10.1038/nrc1188

Guzmán, M., Duarte, M. J., Blázquez, C., Ravina, J., Rosa, M. C., Galve-Roperh, I., et al. (2006). A pilot clinical study of $\Delta 9$-tetrahydrocannabinol in patients with recurrent glioblastoma multiforme. Br. J. Cancer 95, 197-203. doi: 10.1038/sj. bjc. 6603236

Han, Y., Moreira, I. S., Urizar, E., Weinstein, H., and Javitch, J. A. (2009). Allosteric communication between protomers of dopamine class A GPCR dimers modulates activation. Nat. Chem. Biol. 5, 688-695. doi: 10.1038/ nchembio.199

Hanson, S. M., Gurevich, E. V., Vishnivetskiy, S. A., Ahmed, M. R., Song, X., and Gurevich, V. V. (2007). Each rhodopsin molecule binds its own arrestin. Proc. Natl. Acad. Sci. U.S.A. 104, 3125-3128. doi: 10.1073/pnas.0610886104

Hart, S., Fischer, O. M., and Ullrich, A. (2004). Cannabinoids induce cancer cell proliferation via tumor necrosis factor alpha-converting enzyme (TACE/ADAM17)-mediated transactivation of the epidermal growth factor receptor. Cancer Res. 64, 1943-1950. doi: 10.1158/0008-5472.CAN-03-3720

Hashibe, M., Straif, K., Tashkin, D. P., Morgenstern, H., Greenland, S., and Zhang, Z.-F. (2005). Epidemiologic review of marijuana use and cancer risk. Alcohol 35, 265-275. doi: 10.1016/j.alcohol.2005.04.008 
Hauser, A. S., Attwood, M. M., Rask-Andersen, M., Schiöth, H. B., and Gloriam, D. E. (2017). Trends in GPCR drug discovery: new agents, targets and indications. Nat. Rev. Drug Discov. 16, 829-842. doi: 10.1038/nrd.2017.178

Hazekamp, A., and Grotenhermen, F. (2010a). Review on clinical studies with cannabis and cannabinoid 2005-2009. Cannabinoids 5, 1-21.

Hazekamp, A., and Grotenhermen, F. (2010b). Review on clinical studies with cannabis and cannabinoids 2010-2014. Cannabinoids 5, 1-21. doi: 10.1007/9783-319-56645-0_8

He, L., Fong, J., von Zastrow, M., and Whistler, J. L. (2002). Regulation of opioid receptor trafficking and morphine tolerance by receptor oligomerization. Cell 108, 271-282. doi: 10.1016/S0092-8674(02)00613-X

He, S. Q., Zhang, Z. N., Guan, J. S., Liu, H. R., Zhao, B., Wang, H. B., et al. (2011). Facilitation of $\mu$-opioid receptor activity by preventing $\delta$-opioid receptormediated codegradation. Neuron 69, 120-131. doi: 10.1016/j.neuron.2010. 12.001

Henstridge, C. M., Balenga, N. A., Kargl, J., Andradas, C., Brown, A. J., Irving, A., et al. (2011). Minireview: recent developments in the physiology and pathology of the lysophosphatidylinositol-sensitive receptor GPR55. Mol. Endocrinol. 25, 1835-1848. doi: 10.1210/me.2011-1197

Herrick-Davis, K., Grinde, E., Cowan, A., and Mazurkiewicz, J. E. (2013). Fluorescence correlation spectroscopy analysis of serotonin, adrenergic, muscarinic, and dopamine receptor dimerization: the oligomer number puzzle. Mol. Pharmacol. 84, 630-642. doi: 10.1124/mol.113.087072

Herrick-Davis, K., Grinde, E., Lindsley, T., Cowan, A., and Mazurkiewicz, J. E. (2012). Oligomer size of the serotonin 5-hydroxytryptamine 2C (5HT2C) receptor revealed by fluorescence correlation spectroscopy with photon counting histogram analysis: evidence for homodimers without monomers or tetramers. J. Biol. Chem. 287, 23604-23614. doi: 10.1074/jbc.M112. 350249

Herrick-Davis, K., Grinde, E., Lindsley, T., Teitler, M., Mancia, F., Cowan, A., et al. (2015). Native serotonin 5-HT2C receptors are expressed as homodimers on the apical surface of choroid plexus epithelial cells. Mol. Pharmacol. 87, 660-673. doi: 10.1124/mol.114.096636

Herrick-Davis, K., Weaver, B. A., Grinde, E., and Mazurkiewicz, J. E. (2006). Serotonin 5-HT2C receptor homodimer biogenesis in the endoplasmic reticulum: real-time visualization with confocal fluorescence resonance energy transfer. J. Biol. Chem. 281, 27109-27116. doi: 10.1074/jbc.M604 390200

Higgins, M. J., and Baselga, J. (2011). Targeted therapies for breast cancer. J. Clin. Invest. 121, 3797-3803. doi: 10.1172/JCI57152

Hilairet, S., Bouaboula, M., Carrière, D., Le Fur, G., and Casellas, P. (2003). Hypersensitization of the Orexin 1 receptor by the CB1 receptor: evidence for cross-talk blocked by the specific CB1 antagonist, SR141716. J. Biol. Chem. 278, 23731-23737. doi: 10.1074/jbc.M212369200

Hillion, J., Canals, M., Torvinen, M., Casadó, V., Scott, R., Terasmaa, A., et al. (2002). Coaggregation, cointernalization, and codesensitization of adenosine A2A receptors and dopamine D2 receptors. J. Biol. Chem. 277, 18091-18097. doi: 10.1074/jbc.M107731200

Holland, M., Lau, D., Allen, J., and Arnold, J. (2007). The multidrug transporter ABCG2 (BCRP) is inhibited by plant-derived cannabinoids. Br. J. Pharmacol. 152, 815-824. doi: 10.1038/sj.bjp.0707467

Holland, M., Panetta, J., Hoskins, J., Bebawy, M., Roufogalis, B., Allen, J., et al. (2006). The effects of cannabinoids on p-glycoprotein transport and expression in multidrug resistant cells. Biochem. Pharmacol. 71, 1146-1154. doi: 10.1016/j. bcp.2005.12.033

Horswill, J. G., Bali, U., Shaaban, S., Keily, J. F., Jeevaratnam, P., Babbs, A. J., et al. (2007). PSNCBAM-1, a novel allosteric antagonist at cannabinoid CB1 receptors with hypophagic effects in rats. Br. J. Pharmacol. 152, 805-814. doi: 10.1038/sj.bjp.0707347

Hounsou, C., Margathe, J. F., Oueslati, N., Belhocine, A., Dupuis, E., and Thomas, C. (2015). Time-resolved FRET binding assay to investigate hetero-oligomer binding properties: proof of concept with dopamine D1/D3 heterodimer. ACS Chem. Biol. 10, 466-474. doi: 10.1021/cb50 07568

Hua, T., Vemuri, K., Nikas, S. P., Laprairie, R. B., Wu, Y., Qu, L., et al. (2017). Crystal structures of agonist-bound human cannabinoid receptor CB1. Nature 547, 468-471. doi: 10.1038/nature23272
Hua, T., Vemuri, K., Pu, M., Qu, L., Han, G. W., Wu, Y., et al. (2016). Crystal structure of the human cannabinoid receptor CB1. Cell 167, 750-762.e14. doi: 10.1016/j.cell.2016.10.004

Hudson, B. D., Hébert, T. E., and Kelly, M. E. (2010). Physical and functional interaction between CB1 cannabinoid receptors and beta2adrenoceptors. Br. J. Pharmacol. 160, 627-642. doi: 10.1111/j.1476-5381.2010. 00681.x

HUGO G. N. C. Symbol Report for CNR1. Available at: https://www.genenames. org/data/gene-symbol-report/\#!/hgnc_id/HGNC:2159 (accessed December 25, 2018).

HUGOb G. N. C. Symbol Report for CNR2. Available at: https://www.genenames. org/data/gene-symbol-report/\#!/hgnc_id/HGNC:2160 (accessed December 25, 2018).

Hurevich, M., Talhami, A., Shalev, D. E., and Gilon, C. (2014). Allosteric inhibition of g-protein coupled receptor oligomerization: strategies and challenges for drug development. Curr. Top Med. Chem. 14, 1842-1863. doi: 10.2174/ 1568026614666140901130843

Hurst, D. P., Grossfield, A., Lynch, D. L., Feller, S., Romo, T. D., Gawrisch, K., et al. (2010). A lipid pathway for ligand binding is necessary for a cannabinoid G protein-coupled receptor. JBC 285, 17964-17964. doi: 10.1074/jbc.M109. 041590

Iffland, K., and Grotenhermen, F. (2017). An update on safety and side effects of cannabidiol: a review of clinical data and relevant animal studies. Cannabis Cannabinoid Res. 2, 139-154. doi: 10.1089/can.2016.0034

Ignatowska-Jankowska, B. M., Baillie, G. L., Kinsey, S., Crowe, M., Ghosh, S., Owens, R. A., et al. (2015). A cannabinoid CB1 receptor-positive allosteric modulator reduces neuropathic pain in the mouse with no psychoactive effects. Neuropsychopharmacology 40, 2948-2959. doi: 10.1038/npp.2015.148

Izzo, A. A., Aviello, G., Petrosino, S., Orlando, P., Marsicano, G., Lutz, B., et al. (2008). Increased endocannabinoid levels reduce the development of precancerous lesions in the mouse colon. J. Mol. Med. 86, 89-98. doi: 10.1007/ s00109-007-0248-4

Jacobs, B. A., Pando, M. M., Jennings, E., Chavera, T. A., Clarke, W. P., and Berg, K. A. (2018). Allosterism within $\delta$ opioid-к opioid receptor heteromers in peripheral sensory neurons: regulation of $\kappa$ opioid agonist efficacy. Mol. Pharmacol. 93, 376-386. doi: 10.1124/mol.117.109975

Jastrzebska, B., Comar, W. D., Kaliszewski, M. J., Skinner, K. C., Torcasio, M. H., Esway, A. S., et al. (2017). A G protein-coupled receptor dimerization interface in human cone opsins. Biochemistry 56, 61-72. doi: 10.1021/acs.biochem. $6 \mathrm{~b} 00877$

Jin, J., Momboisse, F., Boncompain, G., Koensgen, F., Zhou, Z., Cordeiro, N., et al. (2018). CCR5 adopts three homodimeric conformations that control cell surface delivery. Sci. Signal. 11:eaal2869. doi: 10.1126/scisignal.aal2869

Jonas, K. C., Chen, S., Virta, M., Mora, J., Franks, S., Huhtaniemi, I., et al. (2018). Temporal reprogramming of calcium signalling via crosstalk of gonadotrophin receptors that associate as functionally asymmetric heteromers. Sci. Rep. 8:2239. doi: 10.1038/s41598-018-20722-5

Jonas, K. C., Fanelli, F., Huhtaniemi, I. T., and Hanyaloglu, A. C. (2015). Single molecule analysis of functionally asymmetric G protein-coupled receptor (GPCR) oligomers reveals diverse spatial and structural assemblies. J. Biol. Chem. 290, 3875-3892. doi: 10.1074/jbc.M114.622498

Jonas, K. C., and Hanyaloglu, A. C. (2017). Impact of G protein-coupled receptor heteromers in endocrine systems. Mol. Cell. Endocrinol. 449, 21-27. doi: 10. 1016/j.mce.2017.01.030

Jonas, K. C., Huhtaniemi, I., and Hanyaloglu, A. C. (2016). Single-molecule resolution of G protein-coupled receptor (GPCR) complexes. Methods Cell Biol. 132, 55-72. doi: 10.1016/bs.mcb.2015.11.005

Joosten, M., Valk, P. J., Jorda, M. A., Vankan-Berkhoudt, Y., Verbakel, S., van den Broek, M., et al. (2002). Leukemic predisposition of pSca-1/Cb2 transgenic mice. Exp. Hematol. 30, 142-149. doi: 10.1016/S0301-472X(01)00779-2

Jordan, B. A., and Devi, L. A. (1999). G-protein-coupled receptor heterodimerization modulates receptor function. Nature 399, 697-700. doi: $10.1038 / 21441$

Kalso, E. (2001). Cannabinoids for pain and nausea. BMJ 323, 2-3. doi: 10.1136/ bmj.323.7303.2

Kargl, J., Balenga, N., Parzmair, G. P., Brown, A. J., Heinemann, A., and Waldhoer, M. (2012). The cannabinoid receptor CB1 modulates the signaling 
properties of the lysophosphatidylinositol receptor GPR55. J. Biol. Chem. 287, 44234-44248. doi: 10.1074/jbc.M112.364109

Katritch, V., Cherezov, V., and Stevens, R. C. (2012). Diversity and modularity of G protein-coupled receptor structures. Trends Pharmacol. Sci. 33, 17-27. doi: 10.1016/j.tips.2011.09.003

Kaur, R., Sidhu, P., and Singh, S. (2016). What failed BIA 10-2474 Phase I clinical trial? Global speculations and recommendations for future Phase I trials. J. Pharmacol. Pharmacother. 7, 120-126. doi: 10.4103/0976-500X.189661

Kearn, C. S., Blake-Palmer, K., Daniel, E., Mackie, K., and Glass, M. (2005). Concurrent stimulation of cannabinoid $\mathrm{CB} 1$ and dopamine D2 receptors enhances heterodimer formation: a mechanism for receptor cross-talk? Mol. Pharmacol. 67, 1697-1704. doi: 10.1124/mol.104.006882

Kenakin, T., Agnati, L. F., Caron, M., Fredholm, B., Guidoli, D., Kobilka, B., et al. (2010). International workshop at the Nobel Forum, Karolinska Institutet on G protein-coupled receptors: finding the words to describe monomers, oligomers, and their molecular mechanisms and defining their meaning. Can a consensus be reached? J. Recept. Signal Transduct. 30, 284-286. doi: 10.3109/10799893. 2010.512438

Kenakin, T., and Miller, L. J. (2010). Seven transmembrane receptors as shapeshifting proteins: the impact of allosteric modulation and funcional selectivity on new drug discovery. Pharmacol. Rev. 62, 265-304. doi: 10.1124/ pr.108.000992

Kern, A., Albarran-Zeckler, R., Walsh, H. E., and Smith, R. G. (2012). Apoghrelin receptor forms heteromers with DRD2 in hypothalamic neurons and is essential for anorexigenic effects of DRD2 agonism. Neuron 73, 317-332. doi: 10.1016/j.neuron.2011.10.038

Khajehali, E., Malone, D. T., Glass, M., Sexton, P. M., Christopoulos, A., and Leach, K. (2015). Biased agonism and biased allosteric modulation at the CB1 cannabinoid receptor. Mol. Pharmacol. 88, 368-379. doi: 10.1124/mol.115. 099192

Kniazeff, J., Prezeau, L., Rondard, P., Pin, J. P., and Goudet, C. (2011). Dimers and beyond: the funcional puzzles of class C GPCRs. Pharmacol. Ther. 130, 9-25. doi: 10.1016/j.pharmthera.2011.01.006

Kuszak, A. J., Pitchiaya, S., Anand, J. P., Mosberg, H. I., Walter, N. G., and Sunahara, R. K. (2009). Purification and functional reconstitution of monomeric mu-opioid receptors: allosteric modulation of agonist binding by Gi2. J. Biol. Chem. 284, 26732-26741. doi: 10.1074/jbc.M109.026922

Lao, J., He, H., Wang, X., Wang, Z., Song, Y., Yang, B., et al. (2017). Single-molecule imaging demonstrates ligand regulation of the oligomeric status of CXCR4 in living cells. J. Phys. Chem. B 121, 1466-1474. doi: 10.1021/acs.jpcb.6b10969

Laprairie, R. B., Bagher, A. M., and Denovan-Wright, E. M. (2017a). Cannabinoid receptor ligand bias: implications in the central nervous system. Curr. Opin. Pharmacol. 32, 32-43. doi: 10.1016/j.coph.2016.10.005

Laprairie, R. B., Kulkarni, P. M., Deschamps, J. R., Kelly, M. E. M., Janero, D. R., Cascio, M. G., et al. (2017b). Enantiospecific allosteric modulation of cannabinoid 1 receptor. ACS Chem. Neurosci. 8, 1188-1203. doi: 10.1021/ acschemneuro.6b00310

Laprairie, R. B., Bagher, A. M., Kelly, M. E. M., and Denovan-Wright, E. M. (2015). Cannabidiol is a negative allosteric modulator of the cannabinoid CB1 receptor. Br. J. Pharmacol. 172, 4790-4805. doi: 10.1074/jbc.M112.382481

Lefkowitz, R. J. (2004). Historical review: a brief history and personal retrospective of seven transmembrane receptors. Trends Pharmacol. Sci. 25, 413-422. doi: $10.1016 /$ j.tips.2004.06.006

Liste, M. J., Caltabiano, G., Ward, R. J., Alvarez-Curto, E., Marsango, S., and Milligan, G. (2015). The molecular basis of oligomeric organization of the human M3 muscarinic acetylcholine receptor. Mol. Pharmacol. 87, 936-953. doi: 10.1124/mol.114.096925

Liu, W. M., Scott, K. A., Shamash, J., Joel, S., and Powles, T. B. (2008). Enhancing the in vitro cytotoxic activity of Delta9-tetrahydrocannabinol in leukemic cells through a combinatorial approach. Leuk. Lymphoma 49, 1800-1809. doi: $10.1080 / 10428190802239188$

Lodola, A., Castelli, R., Mor, M., and Rivara, S. (2015). Fatty acid amide hydrolase inhibitors: a patent review (2009-2014). Expert Opin. Ther. Pat. 25, 1247-1266. doi: $10.1517 / 13543776.2015 .1067683$

Lopez-Gimenez, J. F., Canals, M., Pediani, J. D., and Milligan, G. (2007). The $\alpha_{1 b}$-adrenoceptor exists as a higher-order oligomer: effective oligomerization is required for receptor maturation, surface delivery, and function. Mol. Pharmacol. 71, 1015-1029. doi: 10.1124/mol.106.033035
Lorente, M., Torres, S., Salazar, M., Carracedo, A., Hernández-Tiedra, S., Rodríguez-Fornés, F., et al. (2011). Stimulation of the midkine/ALK axis renders glioma cells resistant to cannabinoid antitumoral action. Cell Death Differ. 18, 959-973. doi: 10.1038/cdd.2010.170

Lu, H.-C., and Mackie, K. (2016). An introduction to the endogenous cannabinoid system. Biol. Psychiatry 79, 516-525. doi: 10.1016/j.biopsych.2015.07.028

Łukasiewicz, S., Błasiak, E., Faron-Górecka, A., Polit, A., Tworzydło, M., Górecki, A., et al. (2007). Fluorescence studies of homooligomerization of adenosine A2A and serotonin 5-HT1A receptors reveal the specificity of receptor interactions in the plasma membrane. Pharmacol. Rep. 59, 379-392.

Maertens, R., White, P., Williams, A., and Yauk, C. (2013). A global toxicogenomic analysis investigating the mechanistic differences between tobacco and marijuana smoke condensates in vitro. Toxicology 308, 60-73. doi: 10.1016/j. tox.2013.03.008

Malfitano, A. M., Ciaglia, E., Gangemi, G., Gazzerro, P., Laezza, C., and Bifulco, M. (2011). Update on the endocannabinoid system as an anticancer target. Expert Opin. Ther. Targets 15, 297-308. doi: 10.1517/14728222.2011.553606

Mandrika, I., Petrovska, R., and Klovins, J. (2010). Evidence for constitutive dimerization of niacin receptor subtypes. Biochem. Biophys. Res. Commun. 395, 281-287. doi: 10.1016/j.bbrc.2010.04.011

Marcellino, D., Carriba, P., Filip, M., Borgkvist, A., Frankowska, M., Bellido, I., et al. (2008). Antagonistic cannabinoid CB1/dopamine D2 receptor interactions in striatal CB1/D2 heteromers. A combined neurochemical and behavioral analysis. Neuropharmacology 54, 815-823. doi: 10.1016/j.neuropharm.2007. 12.011

Martínez-Pinilla, E., Reyes-Resina, I., Oñatibia-Astibia, A., Zamarbide, M., Ricobaraza, A., Navarro, G., et al. (2014). CB1 and GPR55 receptors are coexpressed and form heteromers in rat and monkey striatum. Exp. Neurol. 261, 44-52. doi: 10.1016/j.expneurol.2014.06.017

Martínez-Pinilla, E., Varani, K., Reyes-Resina, I., Angelats, E., Vincenzi, F., Ferreiro-Vera, C., et al. (2017). Binding and signaling studies disclose a potential allosteric site for cannabidiol in cannabinoid CB2 receptors. Front. Pharmacol. 8:744. doi: 10.339/fphar.2017.00744

Matsuda, L. A., Lolait, S. J., Brownstein, M. J., Young, A. C., and Bonner, T. I. (1990). Structure of a cannabinoid receptor and functional expression of the cloned cDNA. Nature 346, 561-564. doi: 10.1038/346561a0

May, L. T., Bridge, L. J., Stoddart, L. A., Briddon, S. J., and Hill, S. J. (2011). Allosteric interactions across native adenosine-A3 receptor homodimers: quantification using single-cell ligand-binding kinetics. FASEB J. 25, 3465-3476. doi: 10.1096/fj.11-186296

McDougle, D. R., Watson, J. E., Abdeen, A. A., Adili, R., Caputo, M. P., Krapf, J. E., et al. (2017). Anti-inflammatory omega-3 endocannabinoid epoxides. Proc. Natl. Acad. Sci. U.S.A. 114, E6034-E6043. doi: 10.1073/pnas.16103 25114

McKallip, R. J., Lombard, C., Fisher, M., Martin, B. R., Ryu, S., Grant, S., et al. (2002). Targeting CB2 cannabinoid receptors as a novel therapy to treat malignant lymphoblastic disease. Blood 100, 627-634. doi: 10.1182/blood2002-01-0098

McKallip, R. J., Nagarkatti, M., and Nagarkatti, P. S. (2005). Delta-9tetrahydrocannabinol enhances breast cancer growth and metastasis by suppression of the antitumor immune response. J. Immunol. 174, 3281-3289. doi: $10.4049 /$ jimmunol.174.6.3281

Mechoulam, R., Ben-Shabat, S., Hanus, L., Ligumsky, M., Kaminski, N. E., Schatz, A. R., et al. (1995). Identification of an endogenous 2-monoglyceride, present in canine gut, that binds to cannabinoid receptors. Biochem. Pharmacol. 50, 83-90. doi: 10.1016/0006-2952(95)00109-D

Miyato, H., Kitayama, J., Yamashita, H., Souma, D., Asakage, M., Yamada, J., et al. (2009). Pharmacological synergism between cannabinoids and paclitaxel in gastric cancer cell lines. J. Surg. Res. 155, 40-47. doi: 10.1016/j.jss.2008.06.045

Moasser, M. M. (2007). The oncogene HER2: its signaling and transforming functions and its role in human cancer pathogenesis. Oncogene 26, 6469-6487. doi: 10.1038/sj.onc. 1210477

Molero, A., Vendrell, M., Bonaventura, J., Zachmann, J., López, L., Pardo, L., et al. (2015). A solid-phase combinatorial approach for indoloquinolizidine-peptides with high affinity at $\mathrm{D}(1)$ and $\mathrm{D}(2)$ dopamine receptors. Eur. J. Med. Chem. 97, 173-180. doi: 10.1016/j.ejmech.2015.04.052

Moreira, F. A., and Wotjak, C. T. (2010). Cannabinoids and anxiety. Curr. Top. Behav. Neurosci. 2, 429-450. doi: 10.1007/7854_2009_16 
Moreira, I. S. (2014). Structural features of the G-protein/GPCR interactions. Biochim. Biophys. Acta 1840, 16-33. doi: 10.1016/j.bbagen.2013.08.027

Moreno, E., Andradas, C., Medrano, M., Caffarel, M. M., Pérez-Gómez, E., BlascoBenito, S., et al. (2014). Targeting CB2-GPR55 receptor heteromers modulates cancer cell signaling. J. Biol. Chem. 289, 21960-21972. doi: 10.1074/jbc.M114. 561761

Moreno, E., Chiarlone, A., Medrano, M., Puigdellívol, M., Bibic, L., Howell, L. A., et al. (2018). Singular location and signaling profile of adenosine A2A-cannabinoid CB1 receptor heteromers in the dorsal striatum. Neuropsychopharmacology 43, 964-977. doi: 10.1038/npp.2017.12

Moreno, E., Quiroz, C., Rea, W., Cai, N. S., Mallol, J., Cortés, A., et al. (2017). Functional $\mu$-opioid-galanin receptor heteromers in the ventral tegmental area. J. Neurosci. 37, 1176-1186. doi: 10.1523/JNEUROSCI.2442-16.2016

Munro, S., Thomas, K. L., and Abu-Shaar, M. (1993). Molecular characterization of a peripheral receptor for cannabinoids. Nature 365, 61-65. doi: 10.1038/ $365061 \mathrm{a} 0$

Munson, A. E., Harris, L. S., Friedman, M. A., Dewey, W. L., and Carchman, R. A. (1975). Antineoplastic activity of cannabinoids. J. Natl. Cancer Inst. 55, 597-602. doi: 10.1093/jnci/55.3.597

Nabissi, M., Morelli, M. B., Santoni, M., and Santoni, G. (2012). Triggering of the TRPV2 channel by cannabidiol sensitizes glioblastoma cells to cytotoxic chemotherapeutic agents. Carcinogenesis 34, 48-57. doi: 10.1093/carcin/bgs328

Navarro, G., Cordomí, A., Casadó-Anguera, V., Moreno, E., Cai, N.-S., Cortés, A., et al. (2018). Evidence for functional pre coupled complexes of receptor heteromers and adenylyl cyclase. Nat. Commun. 9:1242. doi: 10.1038/s41467018-03522-3

Navarro, G., Cordomí, A., Zelman-Femiak, M., Brugarolas, M., Moreno, E., Aguinaga, D., et al. (2016). Quaternary structure of a G-protein-coupled receptor heterotetramer in complex with Gi and Gs. BMC Biol. 14:26. doi: 10.1186/s12915-016-0247-4

Navarro, G., Ferré, S., Cordomi, A., Moreno, E., Mallol, J., Casadó, V., et al. (2010). Interactions between intracellular domains as key determinants of the quaternary structure and function of receptor heteromers. J. Biol. Chem. 285, 27346-27359. doi: 10.1074/jbc.M110.115634

Navarro, H. A., Howard, J. L., Pollard, G. T., and Carroll, F. I. (2009). Positive allosteric modulation of the human cannabinoid (CB) receptor by RTI-371, a selective inhibitor of the dopamine transporter. Br. J. Pharmacol. 156, 1178-1184. doi: 10.1111/j.1476-5381.2009.00124.x

Negro, A., Brar, B. K., Gu, Y., Peterson, K. L., Vale, W., and Lee, K. F. (2006). erbB2 is required for $\mathrm{G}$ protein-coupled receptor signaling in the heart. Proc. Natl. Acad. Sci. U.S.A. 103, 15889-15893. doi: 10.1073/pnas.0607499103

Nemoto, W., Yamanishi, Y., Limviphuvadh, V., Saito, A., and Toh, H. (2016). GGIP: structure and sequence-based GPCR-GPCR interaction pair predictor. Proteins 84, 1224-1233. doi: 10.1002/prot.25071

Ng, S. Y., Lee, L. T., and Chow, B. K. (2013). Receptor oligomerization: from early evidence to current understanding in class B GPCRs. Front. Endocrinol. 3:175. doi: $10.3389 /$ fendo.2012.00175

Nguyen, T., Li, J. X., Thomas, B. F., Wiley, J. L., Kenakin, T. P., and Zhang, Y. (2017). Allosteric modulation: an alternate approach targeting the cannabinoid CB1 receptor. Med. Res. Rev. 37, 441-474. doi: 10.1002/med.21418

Nicolussi, S., and Gertsch, J. (2015). Endocannabinoid transport revisited. Vitam. Horm. 98, 441-485. doi: 10.1016/bs.vh.2014.12.011

Nikan, M., Nabavi, S. M., and Manayi, A. (2016). Ligands for cannabinoid receptors, promising anticancer agents. Life Sci. 146, 124-130. doi: 10.1016/j. lfs.2015.12.053

Nimczick, M., and Decker, M. (2015). New approaches in the design and development of cannabinoid receptor ligands: multifunctional and bivalent compounds. ChemMedChem 10, 773-786. doi: 10.1002/cmdc.201500041

Nomura, D. K., Long, J. Z., Niessen, S., Hoover, H. S., Ng, S. W., and Cravatt, B. F. (2010). Monoacylglycerol lipase regulates a fatty acid network that promotes cancer pathogenesis. Cell 140, 49-61. doi: 10.1016/j.cell.2009.11.027

Ogawa, S., and Kunugi, H. (2015). Inhibitors of fatty acid amide hydrolase and monoacylglycerol lipase: new targets for future antidepressants. Curr. Neuropharmacol. 13, 760-775. doi: 10.2174/1570159X13666150612225212

Orru, M., Bakešová, J., Brugarolas, M., Quiroz, C., Beaumont, V., Goldberg, S. R., et al. (2011). Striatal pre- and postsynaptic profile of adenosine A(2A) receptor antagonists. PLoS One 6:e16088. doi: 10.1371/journal.pone.0016088

Pacher, P., Batkai, S., and Kunos, G. (2006). The endocannabinoid system as an emerging target of pharmacotherapy. Pharmacol. Rev. 58, 389-462. doi: $10.1124 /$ pr.58.3.2
Pagano, E., and Borrelli, F. (2017). Targeting cannabinoid receptors in gastrointestinal cancers for therapeutic uses: current status and future perspectives. Expert Rev. Gastroenterol. Hepatol. 11, 871-873. doi: 10.1080/ 17474124.2017.1367663

Pagano, E., Borrelli, F., Orlando, P., Romano, B., Monti, M., Morbidelli, L., et al. (2017). Pharmacological inhibition of MAGL attenuates experimental colon carcinogenesis. Pharmacol. Res. 119, 227-236. doi: 10.1016/j.phrs.2017.02.002

Pamplona, F. A., Ferreira, J., Menezes de Lima, O. Jr., Duarte, F. S., Bento, A. F., Forner, S., et al. (2012). Anti-inflammatory lipoxin A4 is an endogenous allosteric enhancer of CB1 cannabinoid receptor. Proc. Natl. Acad. Sci. U.S.A. 109, 21134-21139. doi: 10.1073/pnas. 1202906109

Pandey, P., Roy, K. K., and Doerksen, R. J. (2019). Negative allosteric modulators of cannabinoid receptor 2: protein modeling, binding site identification and molecular dynamics simulations in the presence of an orthosteric agonist. J. Biomol. Struct. Dyn. doi: 10.1080/07391102.2019.1567384 [Epub ahead of print].

Panlilio, L. V., Thorndike, E. B., Nikas, S. P., Alapafuja, S. O., Bandiera, T., Cravatt, B. F., et al. (2016). Effects of fatty acid amide hydrolase (FAAH) inhibitors on working memory in rats. Psychopharmacology 233, 1879-1888. doi: 10.1007/ s00213-015-4140-6

Parmar, V. K., Grinde, E., Mazurkiewicz, J. E., and Herrick-Davis, K. (2017). Beta2adrenergic receptor homodimers: role of transmembrane domain 1 and helix 8 in dimerization and cell surface expression. Biochim. Biophys. Acta Biomembr. 1859(9 Pt A), 1445-1455. doi: 10.1016/j.bbamem.2016.12.007

Patsos, H. A., Greenhough, A., Hicks, D. J., Al Kharusi, M., Collard, T. J., Lane, J. D., et al. (2010). The endogenous cannabinoid, anandamide, induces COX-2dependent cell death in apoptosis-resistant colon cancer cells. Int. J. Oncol. 37, 187-193.

Pediani, J. D., Ward, R. J., Godin, A. G., Marsango, S., and Milligan, G. (2016). Dynamic regulation of quaternary organization of the M1 muscarinic receptor by subtype-selective antagonist drugs. J. Biol. Chem. 291, 13132-13146. doi: 10.1074/jbc.M115.712562

Pérez-Gómez, E., Andradas, C., Blasco-Benito, S., Caffarel, M. M., GarcíaTaboada, E., Villa-Morales, M., et al. (2015). Role of cannabinoid receptor CB2 in HER2 pro-oncogenic signaling in breast cancer. J. Natl. Cancer Inst. 107:djv077. doi: 10.1093/jnci/djv077

Pérez-Gómez, E., Andradas, C., Flores, J. M., Quintanilla, M., Paramio, J. M., Guzmán, M., et al. (2013). The orphan receptor GPR55 drives skin carcinogenesis and is upregulated in human squamous cell carcinomas. Oncogene 32, 2534-2542. doi: 10.1038/onc.2012.278

Perou, C. M., Sorlie, T., Eisen, M. B., van de Rijn, M., Jeffrey, S. S., Rees, C. A., et al. (2000). Molecular portraits of human breast tumours. Nature 406, 747-752. doi: $10.1038 / 35021093$

Pertwee, R. G. (2015). "Endocannabinoids and their pharmacological actions," in Handbook of Experimental Pharmacology: Endocannabinoids, ed. R. G. Pertwee (Cham: Springer International Publishing), 1-37.

Pertwee, R. G., Pertwee, R. G., Howlett, A. C., Abood, M. E., Alexander, S. P., Di Marzo, V., et al. (2010). International union of basic and clinical pharmacology. LXXIX. Cannabinoid receptors and their ligands: beyond CB1 and CB2. Pharmacol. Rev. 62, 588-631. doi: 10.1124/pr.110.003004

Peterson, C. D., Kitto, K. F., Akgün, E., Lunzer, M. M., Riedl, M. S., Vulchanova, L., et al. (2017). Bivalent ligand that activates mu opioid receptor and antagonizes mGluR5 receptor reduces neuropathic pain in mice. Pain 158, 2431-2441. doi: 10.1097/j.pain.0000000000001050

Petrucci, V., Chicca, A., Glasmacher, S., Paloczi, J., Cao, Z., Pacher, P., et al. (2017). Pepcan 12 (RVD-hemopressin) is a CB2 receptor positive allosteric modulator constitutively secreted by adrenals and in liver upon tissue damage. Sci. Rep. 7:9560. doi: 10.1038/s41598-017-09808-8

Piñeiro, R., Maffucci, T., and Falasca, M. (2011). The putative cannabinoid receptor GPR55 defines a novel autocrine loop in cancer cell proliferation. Oncogene 30, 142-152. doi: 10.1038/onc.2010.417

Pisanti, S., and Bifulco, M. (2009). Endocannabinoid system modulation in cancer biology and therapy. Pharmacol. Res. 60, 107-116. doi: 10.1002/ijc.24483

Pisanti, S., Borselli, C., Oliviero, O., Laezza, C., Gazzerro, P., and Bifulco, M. (2007). Antiangiogenic activity of the endocannabinoid anandamide: correlation to its tumor-suppressor efficacy. J. Cell. Physiol. 211, 495-503. doi: 10.1002/jcp.20954

Portella, G., Laezza, C., Laccetti, P., De Petrocellis, L., Di Marzo, V., and Bifulco, M. (2003). Inhibitory effects of cannabinoid CB1 receptor stimulation on tumor growth and metastatic spreading: actions on signals involved in angiogenesis and metastasis. FASEB J. 17, 1771-1773. doi: 10.1096/fj.02-1129fje 
Pou, C., Mannoury la Cour, C., Stoddart, L. A., Millan, M. J., and Milligan, G. (2012). Functional homomers and heteromers of dopamine D2L and D3 receptors co-exist at the cell surface. J. Biol. Chem. 287, 8864-8878. doi: 10.1074/ jbc.M111.326678

Preet, A., Ganju, R. K., and Groopman, J. E. (2008). Delta9-Tetrahydrocannabinol inhibits epithelial growth factor-induced lung cancer cell migration in vitro as well as its growth and metastasis in vivo. Oncogene 27, 339-346. doi: 10.1038/sj. onc. 1210641

Price, M. R., Baillie, G. L., Thomas, A., Stevenson, L. A., Easson, M., Goodwin, R., et al. (2005). Allosteric modulation of the cannabinoid CB1 receptor. Mol. Pharmacol. 68, 1484-1495. doi: 10.1124/mol.105.016162

Pulido, D., Casadó-Anguera, V., Pérez-Benito, L., Moreno, E., Cordomí, A., López, L., et al. (2018). Design of a true bivalent ligand with picomolar binding affinity for a $\mathrm{G}$ protein-coupled receptor homodimer. J. Med. Chem. 61, 9335-9346. doi: 10.1021/acs.jmedchem.8b01249

Pyne, N. J., and Pyne, S. (2011). Receptor tyrosine kinase-G-protein-coupled receptor signalling platforms: out of the shadow? Trends Pharmacol. Sci. 32, 443-450. doi: 10.1016/j.tips.2011.04.002

Qamri, Z., Preet, A., Nasser, M. W., Bass, C. E., Leone, G., Barsky, S. H., et al. (2009). Synthetic cannabinoid receptor agonists inhibit tumor growth and metastasis of breast cancer. Mol. Cancer Ther. 8, 3117-3129. doi: 10.1158/1535-7163.MCT09-0448

Qian, M., Vasudevan, L., Huysentruyt, J., Risseeuw, M. D. P., Stove, C., Vanderheyden, P. M. L., et al. (2018a). Design, synthesis, and biological evaluation of bivalent ligands targeting dopamine D2 -like receptors and the $\mu$-opioid receptor. ChemMedChem 13, 944-956. doi: 10.1002/cmdc.201700787

Qian, M., Wouters, E., Dalton, J. A. R., Risseeuw, M. D. P., Crans, R. A. J., Stove, C., et al. (2018b). Synthesis toward bivalent ligands for the dopamine D2 and metabotropic glutamate 5 receptors. J. Med. Chem. 61, 8212-8225. doi: 10.1021/acs.jmedchem.8b00671

Ramer, R., and Hinz, B. (2008). Inhibition of cancer cell invasion by cannabinoids via increased expression of tissue inhibitor of matrix metalloproteinases-1. J. Natl. Cancer Inst. 100, 59-69. doi: 10.1093/jnci/djm268

Ramer, R., and Hinz, B. (2017). Cannabinoids as anticancer drugs. Adv. Pharmacol. 80, 397-436. doi: 10.1016/bs.apha.2017.04.002

Reece, A. S. (2009). Chronic toxicology of cannabis. Clin. Toxicol. 47, 517-524. doi: 10.1080/15563650903074507

Rios, C., Gomes, I., and Devi, L. A. (2006). Opioid and CB1 cannabinoid receptor interactions: reciprocal inhibition of receptor signaling and neuritogenesis. $\mathrm{Br}$. J. Pharmacol. 148, 387-395. doi: 10.1038/sj.bjp.0706757

Rivera-Oliver, M., Moreno, E., Álvarez-Bagnarol, Y., Ayala-Santiago, C., CruzReyes, N., Molina-Castro, G. C., et al. (2018). Adenosine A1-dopamine D1 receptor heteromers control the excitability of the spinal motoneuron. Mol. Neurobiol. 56, 797-811. doi: 10.1007/s12035-018-1120-y

Roth, S. (1978). Stereoselective presynaptic inhibitory effect of delta-9tetrahydrocannabinol on cholinergic transmission in the myenteric plexus of the guinea pig. Can. J. Physiol. Pharmacol. 56, 968-975. doi: 10.1139/y78-154

Rozenfeld, R., Gupta, A., Gagnidze, K., Lim, M. P., Gomes, I., Lee-Ramos, D., et al. (2011). AT1R-CB(1)R heteromerization reveals a new mechanism for the pathogenic properties of angiotensin II. EMBO J. 30, 2350-2363. doi: 10.1038/ emboj.2011.139

Russo, E. B. (2016). Clinical endocannabinoid deficiency reconsidered: current research supports the theory in migraine, fibromyalgia, irritable bowel, and other treatment-resistant syndromes. Cannabis Cannabinoid Res. 1, 154-165. doi: 10.1089/can.2016.0009

Salazar, M., Carracedo, A., Salanueva, I. J., Hernandez-Tiedra, S., Lorente, M., Egia, A., et al. (2009). Cannabinoid action induces autophagy-mediated cell death through stimulation of ER stress in human glioma cells. J. Clin. Invest. 119, 1359-1372. doi: 10.1038/cdd.2011.32

Sanchez, C., de Ceballos, M. L., del Pulgar, T. G., Rueda, D., Corbacho, C., Velasco, G., et al. (2001). Inhibition of glioma growth in vivo by selective activation of the CB (2) cannabinoid receptor. Cancer Res. 61, 5784-5789.

Sañudo-Peña, M. C., Romero, J., Seale, G. E., Fernandez-Ruiz, J. J., and Walker, J. M. (2000). Activational role of cannabinoids on movement. Eur. J. Pharmacol. 391, 269-274. doi: 10.1016/S0014-2999(00)00044-3

Sarfaraz, S., Adhami, V. M., Syed, D. N., Afaq, F., and Mukhtar, H. (2008). Cannabinoids for cancer treatment: progress and promise. Cancer Res. 68, 339-342. doi: 10.1158/0008-5472.CAN-07-2785
Savinainen, J. R., Saario, S. M., and Laitinen, J. T. (2012). The serine hydrolases MAGL, ABHD6 and ABHD12 as guardians of 2-arachidonoylglycerol signalling through cannabinoid receptors. Acta Physiol. 204, 267-276. doi: 10.1111/j.1748-1716.2011.02280.x

Scarlett, K. A., White, E. Z., Coke, C. J., Carter, J. R., Bryant, L. K., Hinton, C. V., et al. (2018). Agonist-induced CXCR4 and CB2 heterodimerization inhibits Galpha13/RhoA-mediated migration. Mol. Cancer Res. 16, 728-739. doi: 10.1158/1541-7786.MCR-16-0481

Scarselli, M., Annibale, P., McCormick, P. J., Kolachalam, S., Aringhieri, S., Radenovic, A., et al. (2016). Revealing G-protein-coupled receptor oligomerization at the single-molecule level through a nanoscopic lens: methods, dynamics and biological function. FEBS J. 283, 1197-1217. doi: $10.1111 /$ febs.13577

Scott, C. E., and Kendall, D. A. (2017). Assessing allosteric modulation of CB1 at the receptor and cellular levels. Methods Enzymol. 593, 317-342. doi: 10.1016/ bs.mie.2017.05.002

Shao, Z., Yin, J., Chapman, K., Grzemska, M., Clark, L., Wang, J., et al. (2016). High-resolution crystal structure of the human CB1 cannabinoid receptor. Nature doi: 10.1038/nature20613 [Epub ahead of print]. doi: 10.1038/ nature20613

Sharman, J. L., and Mpamhanga, C. P. (2011). IUPHAR-DB: an open-access, expert-curated resource for receptor and ion channel research. ACS Chem. Neurosci. 2, 232-235. doi: 10.1021/cn200025w

Shimada, I., Ueda, T., Kofuku, Y., Eddy, M. T., and Wüthrich, K. (2018). GPCR drug discovery: integrating solution NMR data with crystal and cryo-EM structures. Nat. Rev. Drug Discov. doi: 10.1038/nrd.2018.180 [Epub ahead of print]. doi: 10.1038/nrd.2018.180

Shonberg, J., Kling, R. C., Gmeiner, P., and Löber, S. (2015). GPCR crystal structures: medicinal chemistry in the pocket. Bioorg. Med. Chem. 23, 38803906. doi: 10.1016/j.bmc.2014.12.034

Shore, D. M., Baillie, G. L., Hurst, D. H., Navas, F. III, Seltzman, H. H., Marcu, J. P., et al. (2014). Allosteric modulation of a cannabinoid G protein-coupled receptor: binding site Elucidation and relationship to $G$ protein signaling. J. Biol. Chem. 289, 5828-5845. doi: 10.1074/jbc.M113.478495

Sim-Selley, L. J. (2003). Regulation of cannabinoid CB1 receptors in the central nervous system by chronic cannabinoids. Crit. Rev. Neurobiol. 15, 91-119. doi: 10.1615/CritRevNeurobiol.v15.i2.10

Smith, N. J., and Milligan, G. (2010). Allostery at G protein-coupled receptor homo- and heteromers: uncharted pharmacological landscapes. Pharmacol. Rev. 62, 701-725. doi: 10.1124/pr.110.002667

Soderstrom, K., Soliman, E., and Van Dross, R. (2017). Cannabinoids modulate neuronal activity and cancer by $\mathrm{CB} 1$ and $\mathrm{CB} 2$ receptor-independent mechanisms. Front. Pharmacol. 8:720. doi: 10.3389/fphar.2017.00720

Sohy, D., Parmentier, M., and Springael, J. Y. (2007). Allosteric transinhibition by specific antagonists in CCR2/CXCR4 heterodimers. J. Biol. Chem. 282, 30062-30069. doi: 10.1074/jbc.M705302200

Sorlie, T., Perou, C. M., Tibshirani, R., Aas, T., Geisler, S., Johnsen, H., et al. (2001). Gene expression patterns of breast carcinomas distinguish tumor subclasses with clinical implications. Proc. Natl. Acad. Sci. U.S.A. 98, 10869-10874. doi: 10.1073/pnas.191367098

Sotiriou, C., Neo, S. Y., McShane, L. M., Korn, E. L., Long, P. M., Jazaeri, A., et al. (2003). Breast cancer classification and prognosis based on gene expression profiles from a population-based study. Proc. Natl. Acad. Sci. U.S.A. 100, 10393-10398. doi: 10.1073/pnas.1732912100

Staus, D. P., Strachan, R. T., Manglik, A., Pani, B., Kahsai, A. W., Kim, T. H., et al. (2016). Allosteric nanobodies reveal the dynamic range and diverse mechanisms of G-protein-coupled receptor activation. Nature 535, 448-452. doi: $10.1038 /$ nature 18636

Stornaiuolo, M., Bruno, A., Botta, L., La Regina, G., Cosconati, S., Silvestri, R., et al. (2015). Endogenous vs exogenous allosteric modulators in GPCRs: a dispute for shuttling CB1 among different membrane microenvironments. Sci. Rep. 5:15453. doi: $10.1038 /$ srep 15453

Sulcova, E., Mechoulam, R., and Fride, E. (1998). Biphasic effects of anandamide. Pharmacol. Biochem. Behav. 59, 347-352. doi: 10.1016/S0091-3057(97)00422-X

Szalai, B., Barkai, L., Turu, G., Szidonya, L., Várnai, P., and Hunyady, L. (2012). Allosteric interactions within the AT1 angiotensin receptor homodimer: role of the conserved DRY motif. Biochem. Pharmacol. 84, 477-485. doi: 10.1016/j.bcp. 2012.04.014 
Tabor, A., Weisenburger, S., Banerjee, A., Purkayastha, N., Kaindl, J. M., Hübner, H., et al. (2016). Visualization and ligand induced modulation of dopamine receptor dimerization at the single molecule level. Sci. Rep. 6:33233. doi: $10.1038 /$ srep33233

Tan, W. C., Lo, C., Jong, A., Xing, L., Fitzgerald, M. J., Vollmer, W. M., et al. (2009). Marijuana and chronic obstructive lung disease: a population-based study. CMAJ 180, 814-820. doi: 10.1503/cmaj.081040

Teichmann, A., Gibert, A., Lampe, A., Grzesik, P., Rutz, C., Furkert, J., et al. (2014). The specific monomer/dimer equilibrium of the corticotropin-releasing factor receptor type 1 is established in the endoplasmic reticulum. J. Biol. Chem. 289, 24250-24262. doi: 10.1074/jbc.M114.553644

Teitler, M., Toohey, N., Knight, J. A., Klein, M. T., and Smith, C. (2010). Clozapine and other competitive antagonists reactivate risperidone-inactivated h5-HT7 receptors: radioligand binding and functional evidence for GPCR homodimer protomer interactions. Psychopharmacology 212, 687-697. doi: 10.1007/s00213010-2001-x

Terrillon, S., Barberis, C., and Bouvier, M. (2004). Heterodimerization of V1a and V2 vasopressin receptors determines the interaction with beta-arrestin and their trafficking patterns. Proc. Natl. Acad. Sci. U.S.A. 101, 1548-1553. doi: 10.1073/pnas.0305322101

Thomas, C. (2001). U.S. v. Oakland Cannabis Buyer's Cooperative. Available at: https://supreme.justia.com/cases/federal/us/532/483/case.pdf (accessed December 25, 2018).

Thors, L., Bergh, A., Persson, E., Hammarsten, P., Stattin, P., Egevad, L., et al. (2010). Fatty acid amide hydrolase in prostate cancer: association with disease severity and outcome, CB1 receptor expression and regulation by IL-4. PLoS One 5:e12275. doi: 10.1371/journal.pone.0012275

Tian, H., Fürstenberg, A., and Huber, T. (2017). Labeling and single-molecule methods to monitor $G$ protein-coupled receptor dynamics. Chem. Rev. 117, 186-245. doi: 10.1021/acs.chemrev.6b00084

Tramèr, M. R., Carroll, D., Campbell, F. A., Reynolds, D. J., Moore, R. A., and McQuay, H. J. (2001). Cannabinoids for control of chemotherapy induced nausea and vomiting: quantitative systematic review. BMJ 323, 16-21. doi: 10.1136/bmj.323.7303.16

UniProtKB P. Knowledgebase UniProtKB - P21554 (CNR1_HUMAN). Available at: https://www.uniprot.org/uniprot/P21554 (accessed December 25, 2018).

UniProtKBb P. Knowledgebase UniProtKB - P34972 (CNR2_HUMAN). Available at: https://www.uniprot.org/uniprot/P34972 (accessed December 25, 2018).

Vallée, M., Vitiello, S., Bellocchio, L., Hébert-Chatelain, E., Monlezun, S., MartinGarcia, E., et al. (2014). Pregnenolone can protect the brain from cannabis intoxication. Science 343, 94-98. doi: 10.1126/science.1243985

Vara, D., Salazar, M., Olea-Herrero, N., Guzmán, M., Velasco, G., and DiazLaviada, I. (2011). Antitumoral action of cannabinoids on hepatocellular carcinoma: role of AMPK-dependent activation of autophagy. Cell Death Differ. 18, 1099-1111. doi: $10.1038 / \mathrm{cdd} .2011 .32$

Varelius, J. (2006). The value of autonomy in medical ethics. Med. Health Care Philos. 9, 377-388. doi: 10.1007/s11019-006-9000-z

Vassilatis, D. K., Hohmann, J. G., Zeng, H., Li, F., Ranchalis, J. E., Mortrud, M. T., et al. (2003). The G protein-coupled receptor repertoires of human and mouse. Proc. Natl. Acad. Sci. U.S.A. 100, 4903-4908. doi: 10.1073/pnas.0230374100

Velasco, G., Sanchez, C., and Guzmán, M. (2012). Towards the use of cannabinoids as antitumour agents. Nat. Rev. Cancer 12, 436-444. doi: 10.1038/nrc3247

Velasco, G., Sánchez, C., and Guzmán, M. (2015). “Endocannabinoids and cancer," in Handbook of Experimental Pharmacology: Endocannabinoids, ed. R. G. Pertwee (Cham: Springer International Publishing), 449-472.

Venkatakrishnan, A. J., Deupi, X., Lebon, G., Tate, C. G., Schertler, G. F., and Babu, M. M. (2013). Molecular signatures of G-protein-coupled receptors. Nature 494, 185-194. doi: 10.1038/nature11896

Vilardaga, J. P., Agnati, L. F., Fuxe, K., and Ciruela, F. (2010). G-protein-coupled receptor heteromer dynamics. J. Cell Sci. 123, 4215-4220. doi: 10.1242/jcs. 063354

Viñals, X., Moreno, E., Lanfumey, L., Cordomí, A., Pastor, A., de La Torre, R., et al. (2015). Cognitive impairment induced by delta9-tetrahydrocannabinol occurs through heteromers between cannabinoid CB1 and serotonin 5-HT2A receptors. PLoS Biol. 13:e1002194. doi: 10.1371/journal.pbio.1002194
Vischer, H. F., Castro, M., and Pin, J. P. (2015). G Protein-coupled receptor multimers: a question still open despite the use of novel approaches. Mol. Pharmacol. 88, 561-571. doi: 10.1124/mol.115.099440

Volkow, N. D., Baler, R. D., Compton, W. M., and Weiss, S. R. B. (2014). Adverse health effects of marijuana use. N. Engl. J. Med. 370, 2219-2227. doi: 10.1056/ NEJMra1402309

Wade, F., Espagne, A., Persuy, M. A., Vidic, J., Monnerie, R., Merola, F., et al. (2011). Relationship between homo-oligomerization of a mammalian olfactory receptor and its activation state demonstrated by bioluminescence resonance energy transfer. J. Biol. Chem. 286, 15252-15259. doi: 10.1074/jbc.M110. 184580

Wang, D., Wang, H., Ning, W., Backlund, M. G., and Dey, S. K. (2008). Loss of cannabinoid receptor 1 accelerates intestinal tumor growth. Cancer Res. 68, 6468-6476. doi: 10.1158/0008-5472.CAN-08-0896

Wang, D., Yu, H., Liu, X., Liu, J., and Song, C. (2017). The orientation and stability of the GPCR-Arrestin complex in a lipid bilayer. Sci. Rep. 7:16985. doi: 10.1038/s41598-017-17243-y

Wells, G. J. (2014). Allosteric modulators of G protein-coupled receptors. Curr. Top. Med. Chem. 14, 1735-1737. doi: 10.2174/1568026614666140826115952

Whorton, M. R., Bokoch, M. P., Rasmussen, S. G., Huang, B., Zare, R. N., and Kobilka, B. (2007). A monomeric G protein-coupled receptor isolated in a highdensity lipoprotein particle efficiently activates its G protein. Proc. Natl. Acad. Sci. U.S.A. 104, 7682-7687. doi: 10.1073/pnas.0611448104

Whorton, M. R., Jastrzebska, B., Park, P. S., Fotiadis, D., Engel, A., Palczewski, K., et al. (2008). Efficient coupling of transducin to monomeric rhodopsin in a phospholipid bilayer. J. Biol. Chem. 283, 4387-4394. doi: 10.1074/jbc. M703346200

Whyte, L. S., Ryberg, E., Sims, N. A., Ridge, S. A., Mackie, K., Greasley, P. J., et al. (2009). The putative cannabinoid receptor GPR55 affects osteoclast function in vitro and bone mass in vivo. Proc. Natl. Acad. Sci. U.S.A. 106, 16511-16516. doi: 10.1073/pnas.0902743106

Wootten, D., Christopoulos, A., and Sexton, P. M. (2013). Emerging paradigms in GPCR allostery: implications for drug discovery. Nat. Rev. Drug Discov. 12, 630-644. doi: 10.1038/nrd4052

Xue, L., Rovira, X., Scholler, P., Zhao, H., Liu, J., Pin, J.-P., et al. (2015). Major ligand-induced rearrangement of the heptahelical domain interface in a GPCR dimer. Nat. Chem. Biol. 11, 134-140. doi: 10.1038/nchembio.1711

Zajac, M., Law, J., Cvetkovic, D. D., Pampillo, M., McColl, L., Pape, C., et al. (2011). GPR54 (KISS1R) transactivates EGFR to promote breast cancer cell invasiveness. PLoS One 6:e21599. doi: 10.1371/journal.pone. 0021599

Zhang, J., Medina-Cleghorn, D., Bernal-Mizrachi, L., Bracci, P. M., Hubbard, A., Conde, L., et al. (2016). The potential relevance of the endocannabinoid, 2arachidonoylglycerol, in diffuse large B-cell lymphoma. Oncoscience 3, 31-41. doi: 10.18632/oncoscience. 289

Zheng, D., Bode, A. M., Zhao, Q., Cho, Y.-Y., Zhu, F., Ma, W.-Y., et al. (2008). The cannabinoid receptors are required for ultraviolet-induced inflammation and skin cancer development. Cancer Res. 68, 3992-3998. doi: 10.1158/0008-5472. CAN-07-6594

Zhu, L. X., Sharma, S., Stolina, M., Gardner, B., Roth, M. D., Tashkin, D. P., et al. (2000). $\Delta$-9-tetrahydrocannabinol inhibits antitumour immunity by a CB2 receptor-mediated, cytokine-dependent pathway. J. Immunol. 165, 373-380. doi: 10.4049/jimmunol.165.1.373

Conflict of Interest Statement: The authors declare that the research was conducted in the absence of any commercial or financial relationships that could be construed as a potential conflict of interest.

Copyright (C) 2019 Moreno, Cavic, Krivokuca, Casadó and Canela. This is an openaccess article distributed under the terms of the Creative Commons Attribution License (CC BY). The use, distribution or reproduction in other forums is permitted, provided the original author(s) and the copyright owner(s) are credited and that the original publication in this journal is cited, in accordance with accepted academic practice. No use, distribution or reproduction is permitted which does not comply with these terms. 